\title{
Evaporation and Condensation Heat Transfer Performance of Flammable Refrigerants in a Brazed Plate Heat Exchanger
}

\section{Sheila C. Palmer W. Vance Payne, II Piotr A. Domanski}

U.S. DEPARTMENT OF COMMERCE Technology Administration Building Environment Division Building and Fire Research Laboratory

National Institute of Standards and Technology

Gaithersburg, MD 20899

July 2000

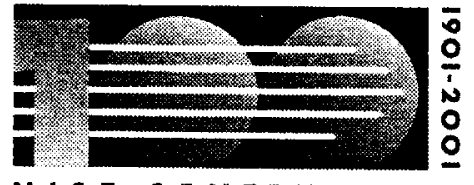

NIST CENTENNIAL:

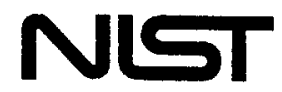

National Institute of Standards and Technology Technology Administration U.S. Department of Commerce 


\section{Evaporation and Condensation Heat Transfer Performance of Flammable Refrigerants in a Brazed Plate Heat Exchanger}

\section{Sheila C. Palmer W. Vance Payne, II Piotr A. Domanski}

U.S. DEPARTMENT OF COMMERCE

Technology Administration Building Environment Division Building and Fire Research Laboratory National Institute of Standards and Technology

Gaithersburg, MD 20899

July 2000

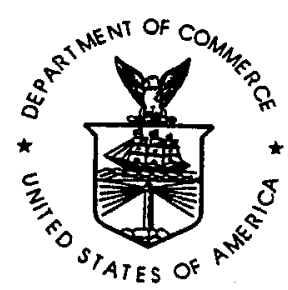

U.S. DEPARTMENT OF COMMERCE William M. Daley, Secretary

TECHNOLOGY ADMINISTRATION Dr. Cheryl L. Shavers, Under Secretary of Commerce for Technology

NATIONAL INSTITUTE OF STANDARDS AND TECHNOLOGY

Raymond G. Kammer, Director 


\section{TABLE OF CONTENTS}

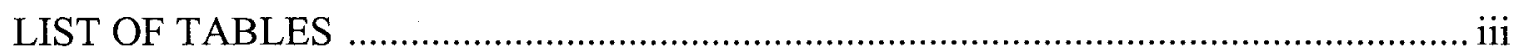

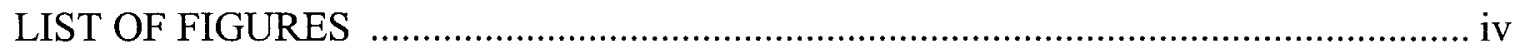

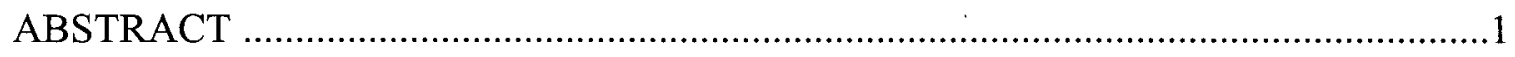

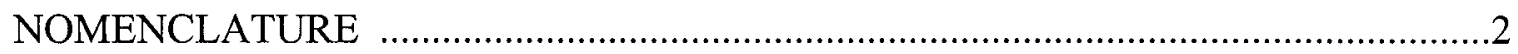

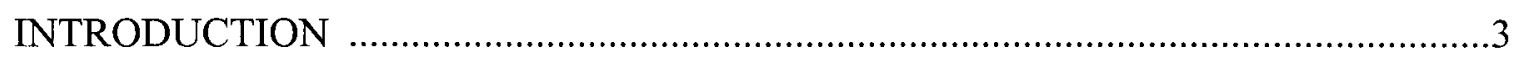

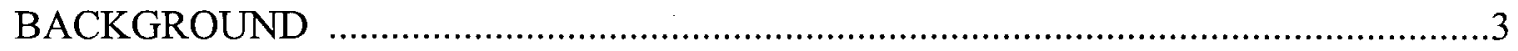

DATA ACQUISITION AND REDUCTION ....................................................

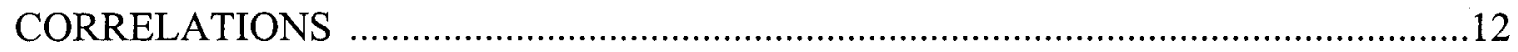

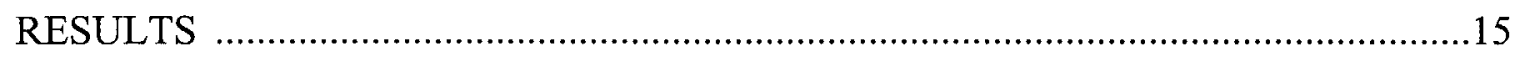

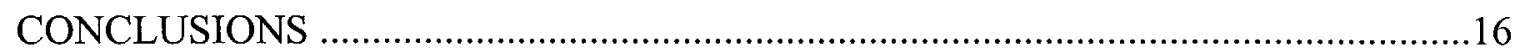

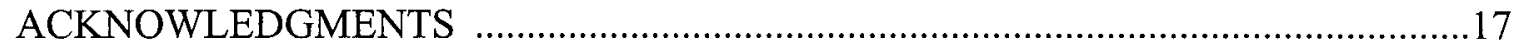

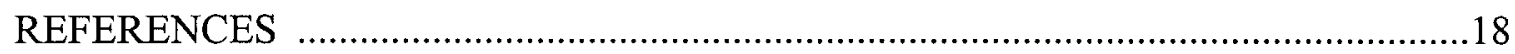

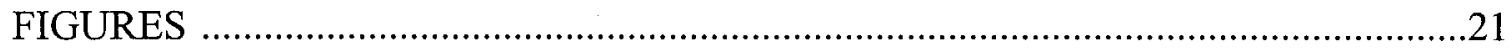




\section{LIST OF TABLES}

1. Geometric specifications of the brazed plate heat exchanger ..................................

2. Comparison of polarities of mixture components ...............................................

3. Average relative difference $(\%)$ in calculated heat transfer rates for refrigerants and HTF .................................................... 10

4. Average expanded relative uncertainties ( $95 \%$ confidence level) for the evaporator ..12

5. Average expanded relative uncertainties ( $95 \%$ confidence level) for the condenser ...12

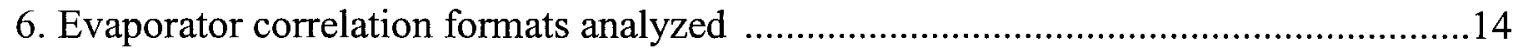

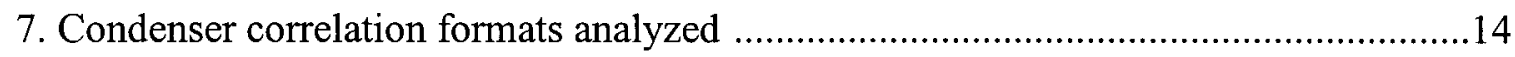

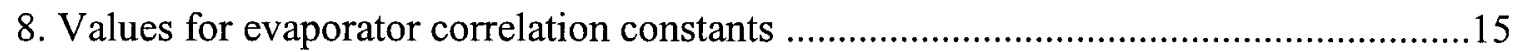

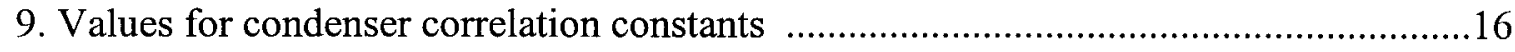




\section{LIST OF FIGURES}

1. Heat and mass flux map for evaporator correlations of interest ...............................21

2. Heat and mass flux map for condenser correlations of interest ..............................21

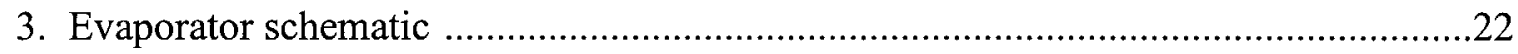

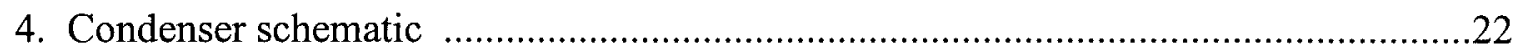

5. Comparison of correlations from literature to current evaporator study ...................23

6. Comparison of correlations from literature to current condenser study .....................23

7. Comparison of evaporative Nusselt numbers for refrigerants in current study ..........24

8. Comparison of condensation Nusselt numbers for refrigerants in current study .........24

9. Evaporative Nusselt number correlation for R22, R290, and R290/ 600a ................25

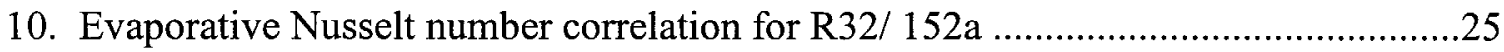

11. Condensation Nusselt number correlation for R22, R290, and R290/ 600a ............26

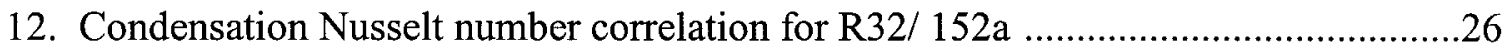




\begin{abstract}
Average Nusselt numbers were measured for R22, R290, R290/600a, and R32/152a undergoing evaporation and condensation in a brazed plate heat exchanger. The refrigerants experienced wavy, stratified flow at low heat and mass fluxes, $1.3 \mathrm{~kW} / \mathrm{m}^{2}$ to $8.3 \mathrm{~kW} / \mathrm{m}^{2}$ and $1.6 \mathrm{~kg} / \mathrm{m}^{2} \mathrm{~s}$ to $19 \mathrm{~kg} / \mathrm{m}^{2} \mathrm{~s}$, respectively. Heat transfer correlations from the literature for in-tube and channel flow of refrigerants with similar heat and mass fluxes were compared to the measured Nusselt numbers. The agreement was found to be unsatisfactory. Evaporation and condensation heat transfer correlations were developed from the data for this study for the combined data of R22, R290, and R290/600a and the data for R32/152a. Separate correlations were needed because the lubricant used for $\mathrm{R} 32 / 152 \mathrm{a}$ was different than the lubricant used for the other refrigerants.
\end{abstract}

Keywords: brazed plate heat exchanger, flammable refrigerants, evaporation, condensation, refrigerant mixtures 


\section{NOMENCLATURE}

\section{English symbols}

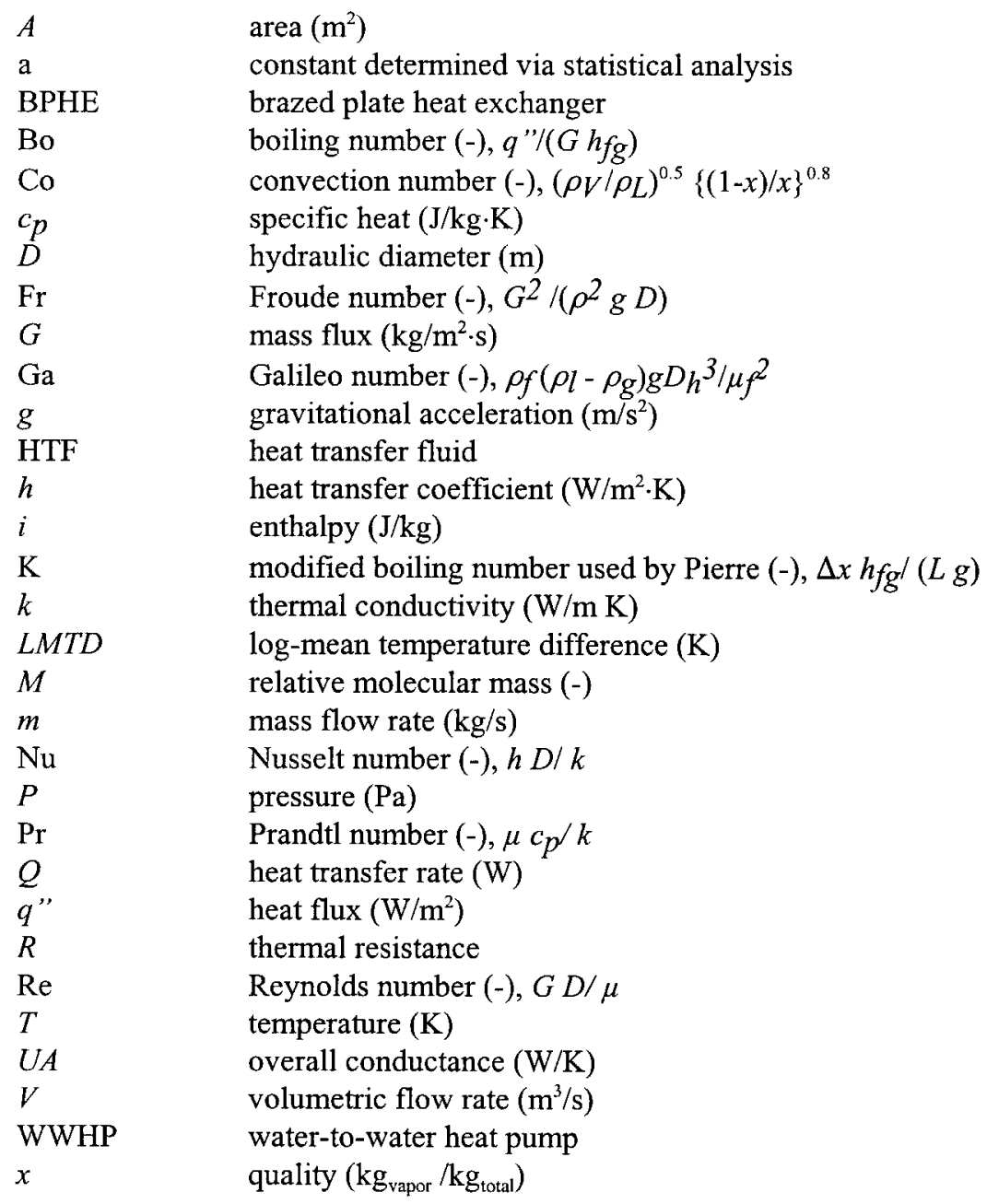

Greek symbols

superscripts

\begin{tabular}{|c|c|c|c|c|c|c|}
\hline$\rho$ & \multicolumn{3}{|l|}{ density $\left(\mathrm{kg} / \mathrm{m}^{3}\right)$} & & \\
\hline$\mu$ & \multicolumn{3}{|c|}{ dynamic viscosity $(\mathrm{kg} / \mathrm{m} \cdot \mathrm{s})$} & $\mathrm{b}$ to $\mathrm{h}$ & \multicolumn{2}{|c|}{$\begin{array}{l}\text { average } \\
\text { constants determined vi }\end{array}$} \\
\hline$\phi$ & \multicolumn{3}{|c|}{ two-phase multiplier $(-),\left(1+12 / \mathrm{X}_{\mathrm{tt}}+1 / \mathrm{X}_{\mathrm{tt}}^{2}\right)^{0.5}$} & & \multicolumn{2}{|c|}{ statistical analysis } \\
\hline $\begin{array}{l}\mathrm{X}_{\mathrm{tt}} \\
\omega\end{array}$ & \multicolumn{3}{|c|}{ Martinelli parameter $(-),\{(1-x) / x\}^{0.9}\left(\rho_{\mathrm{V}} / \rho_{\mathrm{L}}\right)^{0.5}\left(\mu_{\mathrm{L}} / \mu_{\mathrm{V}}\right)^{0.1}$} & ‘ & \multicolumn{2}{|c|}{ alternate definition } \\
\hline \multicolumn{7}{|c|}{$\underline{\text { subscripts }}$} \\
\hline $\mathrm{c}$ & critical & out & outlet & & V & vapor \\
\hline co & condenser & $\mathrm{p}$ & plate & & $\mathrm{w}$ & water/glycol \\
\hline ev & evaporator & $\mathrm{r}$ & refrigerant & & & \\
\hline f & saturated liquid phase & red & reduced & & & \\
\hline g & saturated vapor phase & sat & saturation & & & \\
\hline in & inlet & $\mathrm{sc}$ & subcool & & & \\
\hline $\mathrm{L}$ & liquid & sh & superheat & & & \\
\hline lo & liquid only & tp & two-phase & & & \\
\hline
\end{tabular}




\section{INTRODUCTION}

Concerns about warming of the earth's climate made low global warming potential (GWP) a desired refrigerant attribute. Flammable refrigerants have an inherently low GWP because molecules with hydrogen atoms have short atmospheric lives. However, the use of flammable refrigerants raises safety concerns in the U.S. The safety concerns would be reduced if the systems using flammable refrigerants were designed so that the refrigerant remained outside of the conditioned space. This is accomplished by use of a water-to-water heat pump (WWHP) in which an intermediate heat transfer fluid (HTF) is used between the flammable refrigerant and the air being conditioned. Information must be obtained on the performance of the intermediate heat exchanger in which the HTF and refrigerant interact in order to determine the performance of flammable refrigerants relative to current refrigerants and each other.

Payne et al. (1999) determined the system performance of a WWHP using flammable refrigerants. Data from the system performance study were used to develop a heat transfer correlation for the HTF (glycol/water) in the brazed plate heat exchanger (BPHE) (Gasche, 1998). Data collected as part of the system performance study are used in this study, along with the HTF heat transfer correlation, to determine average heat transfer correlations for R22 (chlorodifluoromethane), R290 (propane), R290/600a (propane/ isobutane), and R32/152a (difluoromethane/ 1,1-difluoroethane) in BPHE evaporators and condensers. Due to the inherent difficulty in instrumenting the interior of a BPHE, all instrumentation for these studies was placed at the inlets and outlets of the BPHE. As such, local heat transfer information is not available and the resulting HTF and refrigerant correlations are for average heat transfer coefficients. While the majority of heat transfer that occurs in the BPHE is the result of a phase change, the average heat transfer coefficients also include a small amount of sensible heat transfer associated with superheated vapor and subcooled liquid refrigerant.

The heat and mass fluxes for this study are low, $1.3 \mathrm{~kW} / \mathrm{m}^{2}$ to $8.3 \mathrm{~kW} / \mathrm{m}^{2}$ and $1.6 \mathrm{~kg} / \mathrm{m}^{2} \cdot \mathrm{s}$ to $19 \mathrm{~kg} / \mathrm{m}^{2} \cdot \mathrm{s}$, respectively, due to the desire for small temperature differences in a BPHE with large surface area. Large surface areas were used to ensure adequate capacity for the system performance study (Payne et al., 1999). Low mass fluxes contribute to the laminar liquid Reynolds numbers, 13 to 230 . Low mass fluxes and Reynolds numbers in combination with the dominance of latent heat transfer and the many changes in flow direction caused by the corrugated plates of the BPHE suggest that the flow may be stratified or wavy. Indeed, comparison of the mass fluxes with Baker's flow pattern map (1954) indicates that the flow is stratified. 


\section{BACKGROUND}

\section{Theory}

The Nusselt number for fully-developed laminar flow in a rectangular channel is constant, its value dependent on the aspect ratio (ratio of width to height) of the channel. The aspect ratio for the BPHE is greater than 80. If the flow in the channels of the BPHE is fully-developed and laminar, the Nusselt number is 8.235 for a constant heat flux boundary condition and 7.54 for a uniform wall temperature boundary condition (Kays, 1980). In a BPHE, the wall temperature changes along the length of the heat exchanger as the fluid temperatures change on each side of the plate. If sensible and latent heat transfer occur in the BPHE, the heat flux may not be constant either. Thus, if the Nusselt number for flow in a BPHE could be approximated as a constant, it would have a value between 7.54 and 8.235 .

In a BPHE, each contact of the corrugated plates re-initiates flow similar to that in an entrance region. The relatively short distance between the contact points also contributes to mixing of the bulk flow. Thus, the flow in a BPHE is not likely to be approximated by the laminar fully-developed Nusselt number. A first attempt to characterize heat transfer in a BPHE might include the use of entry length heat transfer correlations. This would capture the behavior due to continually re-initiated flow but would disregard the mixing that occurs between each re-initiation. In the entry region, the local Nusselt number is often expressed as a function of the Reynolds and Prandtl numbers, the distance from the entrance, and the tube diameter (Incropera and DeWitt, 1990). The passages of the BPHE are such that the entire distance the fluid travels before encountering a change in direction is of the same magnitude as the hydraulic diameter of the BPHE. Thus, the it may be possible to express the Nusselt number as a function of the Reynolds and Prandtl numbers alone. This is one of several possible relationships considered in the present study.

\section{Literature on Evaporation}

A number of studies have been done on the heat transfer and pressure drop characteristics of BPHEs for liquids, e.g., Bogaert and Bolcs (1995) and Tinaut et al. (1992). Thonon et al. (1997) examined the transition from nucleate to convective boiling in compact heat exchangers and concluded that it depends on the product of the boiling number and Martinelli parameter but did not develop a heat transfer correlation.

Kattan et al. (1998) classified flow regimes for heat transfer in horizontal tube flow and developed corresponding local heat transfer correlations. The flow regime of interest for the present study, stratified flow, was one of several for which Kattan et al. did not develop a correlation.

Kedzierski and Kim (1998) examined boiling heat transfer for a variety of pure refrigerants and refrigerant mixtures using a tube with a twisted-tape insert. They developed a correlation for the evaporation heat transfer Nusselt number by hypothesizing that it depended on the Prandtl, Reynolds, and Boiling numbers, the 
reduced pressure, the acentric factor $(\omega)$, and the twist ratio. Since the present study did not use twisted-tape inserts, the twist ratio was not relevant.

Smith et al. (1993) studied refrigerant evaporation in horizontal tubes at low heat and mass fluxes. For this flow regime, wavy/stratified flow, Smith considered several published correlations including those of Kandlikar (1990), Jung et al. (1989), Pierre (1956), and Shah (1982) and then developed new correlations for R12 and R134a, R22/123, and R22/141b. Because few BPHE correlations are available, Smith's R12 and R134a correlation was used by Bansal and Purkayastha (1998) in an $N T U-\varepsilon$ model for alternative refrigerants (R22 and R290) in BPHE. The correlation relates the refrigerant Nusselt number $(\mathrm{Nu})$ to the Nusselt number for the liquid phase of the refrigerant $\left(\mathrm{Nu}_{\mathrm{L}}\right)$ and the boiling number $(\mathrm{Bo})$ :

$$
\mathrm{Nu}=\mathrm{Nu}_{\mathrm{L}}\left[4.3+0.4\left(\mathrm{Bo} \cdot 10^{4}\right)^{1.3}\right]
$$

Because Smith's correlation used heat and mass flux ranges similar to those observed in the present study and has been applied to determine BPHE evaporator capacity, it was chosen for further discussion here. Additional correlations by Smith incorporate the Martinelli parameter $\left(\mathrm{X}_{\mathrm{tt}}\right)$ and the Froude number (Fr). These correlations, for R22/123 and $\mathrm{R} 22 / 114$, respectively, are:

$$
\begin{array}{r}
\mathrm{Nu}=\mathrm{Nu}_{\mathrm{L}}\left[\mathrm{aX}_{\mathrm{tt}}^{\mathrm{b}} \mathrm{Fr}^{\mathrm{c}}+\mathrm{dBo}^{\mathrm{e}}\right] \\
\mathrm{Nu}=\mathrm{aNu}_{\mathrm{L}} \mathrm{X}_{\mathrm{tt}}^{\mathrm{b}} \mathrm{Fr}^{\mathrm{c}} \mathrm{Bo}^{\mathrm{d}}
\end{array}
$$

Two of the published correlations examined by Smith et al. (1993) were deemed unacceptable for use in developing the BPHE correlation for this study, those of Kandlikar (1990) and Jung et al. (1989). Kandlikar's correlation employs an empirical fluid-dependent parameter, $F_{f}$, values of which are not available for all of the fluids considered in the present study. Jung et al. (1989) developed a local evaporative heat transfer correlation for refrigerants in horizontal flow boiling regime which was dependent on bubble contact angle, information that is not available in the present study. In addition, the form of Jung's correlation cannot be linearized, a restriction placed on correlations considered in the present study to assure that all statistical analyses could be carried out with equal accuracy. The heat and mass flux regions for the remaining correlations considered by Smith et al. (1993) are illustrated in Figure 1.

Pierre (1956) developed a model for evaporation of R12 and R22 inside plain horizontal tubes. The overall form of the average Nusselt number $(\overline{\mathrm{Nu}})$ is given as:

where:

$$
\overline{\mathrm{Nu}}=\mathrm{aRe}_{\mathrm{lo}} \mathrm{K}^{\mathrm{b}}
$$

$$
\operatorname{Re}_{10}=\frac{G D}{\mu_{f}}
$$


Shah (1982) developed local heat transfer correlations for vertical and horizontal flow in tubes and annuli and expressed the Nusselt number as a function of the liquid Nusselt number, the Froude number, and the convection number $(\mathrm{Co})$ :

$$
\mathrm{Nu}=\mathrm{aNu}_{\mathrm{L}} \mathrm{Fr}^{\mathrm{b}} \mathrm{Co}^{\mathrm{c}}
$$

\section{Literature on Condensation}

Figure 2 is a map representing some of the condensation correlations found in the literature. The map also contains information on the heat and mass fluxes of interest in the present study. A discussion of the details of the correlations from the literature is provided below.

Panchal (1984) studied the condensation of ammonia and R22 in plate-fin heat exchangers to determine the overall heat transfer coefficient. A correlation was not developed. Guo and Anand (1999) developed a correlation for the condensation of $\mathrm{R} 410 \mathrm{~A}$ in rectangular channels, meant to simulate the flow channels in plate-fin heat exchangers. The mass flux range considered was $30 \mathrm{~kg} / \mathrm{m}^{2} \cdot \mathrm{s}$ to $200 \mathrm{~kg} / \mathrm{m}^{2} \cdot \mathrm{s}$. From the information provided in the paper, the heat flux range was determined to be approximately $5.6 \mathrm{~kW} / \mathrm{m}^{2}$ to $38 \mathrm{~kW} / \mathrm{m}^{2}$.

Soliman et al. (1968) developed a correlation for condensing heat transfer with turbulent flow based on the liquid shear stress at the tube wall. Fluids considered had Prandtl numbers ranging from one to ten. Calculation of the wall shear stress required knowledge of local quality and thermophysical properties. The heat and mass flux ranges for which the correlation holds were not specified. This correlation was not pursued further here due to the lack of information on the heat and mass fluxes.

Traviss et al. (1973) developed a heat transfer correlation for in-tube condensation of R12 and R22 which was dependent on the liquid phase Reynolds and Prandtl $\left(\mathrm{Pr}_{\mathrm{L}}\right)$ numbers and the Martinelli parameter. The heat flux range considered was approximately $8 \mathrm{~kW} / \mathrm{m}^{2}$ to $85 \mathrm{~kW} / \mathrm{m}^{2}$. The mass flux range was $784 \mathrm{~kg} / \mathrm{m}^{2} \cdot \mathrm{s}$ to $7450 \mathrm{~kg} / \mathrm{m}^{2} \cdot \mathrm{s}$. For the liquid Reynolds numbers of interest in the present study, the correlation is:

$$
\begin{gathered}
\mathrm{Nu}=\frac{f\left(\mathrm{X}_{\mathrm{tt}}\right) \operatorname{Pr}_{\mathrm{L}} \operatorname{Re}_{\mathrm{L}}^{0.9}}{\mathrm{~F}_{2}} \\
\mathrm{~F}_{2}=5 \operatorname{Pr}_{\mathrm{L}}+5 \ln \left\{1+\operatorname{Pr}_{\mathrm{L}}\left(0.0936 \operatorname{Re}_{\mathrm{L}}^{0.585}-1\right)\right.
\end{gathered}
$$

In order to use this correlation for the data in the present study, $f\left(\mathrm{X}_{\mathrm{tt}}\right)$ was assumed to be a linear function of the Martinelli parameter and the values for the coefficients and exponents in the expression for $\mathrm{F}_{2}$ were assumed to be the same as those given by Traviss (1973). 
Shah (1979) developed a simplified correlation for film condensation of water, R11, R12, R22, R113, methanol, ethanol, benzene, toluene, and trichloroethylene applicable for mass fluxes from approximately $11 \mathrm{~kg} / \mathrm{m}^{2} \cdot \mathrm{s}$ to $211 \mathrm{~kg} / \mathrm{m}^{2} \cdot \mathrm{s}$ and heat fluxes from $0.16 \mathrm{~kW} / \mathrm{m}^{2}$ to $1900 \mathrm{~kW} / \mathrm{m}^{2}$. The correlation allowed determination of the average twophase heat transfer coefficient from the liquid heat transfer coefficient and the reduced pressure $\left(P_{\text {red }}\right)$ :

$$
\mathrm{Nu}=\mathrm{Nu}_{\mathrm{L}}\left(0.55+\frac{2.09}{P_{\text {red }}^{0.38}}\right)
$$

In the correlation developed by Kaushik and Azer (1988) for steam, R113, and R11 in smooth and internally finned tubes, the two-phase Nusselt number was a function of the liquid phase Reynolds and Prandtl numbers, the reduced pressure, and a geometric parameter (the ratio of the hydraulic diameter to the heat exchanger length). In the present study, the same heat exchanger was used to obtain all data. As such, the geometric parameter has no influence on the heat transfer correlation.

For condensation of a variety of refrigerants in tubes with twisted-tape inserts, Kedzierski and Kim (1998) used all of the parameters used by Kaushik and Azer and added the acentric factor and the Jacob number. The Jacob number is the ratio of sensible to latent heats where the sensible heat transfer is determined from the difference between the saturation and wall temperatures. In the present study, wall temperatures were not measured. Thus, the Jacob number could not be evaluated.

The correlation developed by Chitti and Anand (1996) for smooth tube condensation of R22 and R32/125 includes terms that depend on the properties of the HTF. This approach was deemed unacceptable in the present study as it was desired to have a correlation that relied only on measured quantities and calculated properties of the refrigerant.

\section{DATA ACQUISITION AND REDUCTION}

\section{Brazed plate heat exchanger}

BPHEs are used for the evaporator and condenser of the WWHP. In each of these heat exchangers, heat is transferred between the refrigerant and the HTF. The BPHE is described below in Table 1 (SWEP, n.d.). 
Table 1. Geometric specifications of the brazed plate heat exchanger.

\begin{tabular}{|l|l|}
\hline Type & B25-30 \\
\hline Material & ANSI 316 \\
\hline Number of plates & 30 \\
\hline Number of passes per fluid & 1 \\
\hline Number of thermal plates & 28 \\
\hline Number of refrigerant channels & 14 \\
\hline Number of glycol/water channels & 15 \\
\hline Plate thickness & $0.0004 \mathrm{~m}$ \\
\hline Plate gap & $0.002 \mathrm{~m}$ \\
\hline Hydraulic diameter & $0.004 \mathrm{~m}$ \\
\hline Heat transfer area per plate & $0.0546 \mathrm{~m}^{2}$ \\
\hline Total heat transfer area & $1.53 \mathrm{~m}^{2}$ \\
\hline Channel cross-sectional flow area & $0.000226 \mathrm{~m}^{2}$ \\
\hline
\end{tabular}

\section{Experimental setup}

Gasche (1998) and Payne et al. (1999) provide the details on the experimental setup and methods used to acquire the data analyzed in this report. Flow paths and measured data are illustrated in the schematic of Figures 3 and 4 . General test conditions included $3.9{ }^{\circ} \mathrm{C}$ superheating at evaporator outlet and $3.9{ }^{\circ} \mathrm{C}$ subcooling at the condenser outlet. The mixtures considered are zeotropic and experience a temperature glide of approximately $6{ }^{\circ} \mathrm{C}$ during the phase change process.

Data were taken for operation of the WWHP in both heating and cooling modes. The fixed test conditions for the cooling mode are the indoor dry-bulb temperature of $26.7^{\circ} \mathrm{C}$, the temperature of the HTF entering the condenser of $25^{\circ} \mathrm{C}$, and the HTF temperature difference of $5.6{ }^{\circ} \mathrm{C}$ across both the evaporator and condenser. In the heating mode, the fixed test conditions are the indoor dry-bulb temperature of $21.1^{\circ} \mathrm{C}$ and the temperature of the HTF at the evaporator inlet of $0^{\circ} \mathrm{C}$.

\section{Refrigerants analyzed}

The refrigerants tested in the WWHP investigation and originally considered in this study include R22, R290, and mixtures of R290/600a ( $70 / 30$ by mass), R32/152a (50/50 by mass), and R32/290 (50/50 by mass). The R32/290 was not used in developing the correlations described in this report due to an average difference of more than $23 \%$ between the refrigerant and glycol energy balances. The discrepancy was likely due to the very different polarities of R32 and R290. Polarities for refrigerants used in mixtures in this study are provided in Table 2. The dipole moments (polarities) of R290 and R600a are similar in magnitude as are the dipole moments for R32 and R152a. The dipole moments of R32 and R290 are, however, quite different. The property model for mixtures used in REFPROP 6.01, the source for all property data for this study, was developed from experimental data for binary mixtures with components of similar 
polarities and, most likely, cannot accurately simulate properties of mixtures of refrigerants with significantly different polarities (McLinden, 1999).

Table 2. Comparison of polarities of mixture components.

\begin{tabular}{||l||c|c||}
\hline \multirow{2}{*}{ Mixture components $(1 / 2)$} & \multicolumn{2}{|c||}{ Dipole moment at normal boiling point (debye) } \\
\cline { 2 - 3 } & Component 1 & Component 2 \\
\hline \hline R290/600a & 0.000 & 0.132 \\
\hline R32/152a & 1.978 & 2.262 \\
\hline R32/290 & 1.978 & 0.000 \\
\hline
\end{tabular}

\section{Data analysis}

The following assumptions were made in analyzing the data:

1. steady-state operation,

2. heat loss to the surroundings is negligible,

3. fluid flow is equally distributed throughout all channels of the heat exchanger,

4. no conduction occurs via channel walls or the fluid itself in the direction of fluid flow, and

5. thermal properties of the working fluids are constant throughout the heat exchangers and can be evaluated at an average temperature.

For the evaporator, the temperature used to evaluate thermophysical properties of the refrigerant is determined by averaging the saturation pressure calculated from the measured inlet temperature and outlet pressure. The average temperature of the refrigerant is then taken as the saturation temperature at this average pressure. For the condenser, the refrigerant temperature used for evaluating thermal properties is the average of the saturation temperatures evaluated at the measured inlet and outlet condenser pressures.

The overall energy balance for both the evaporator and condenser is:

$$
Q_{\mathrm{w}}=(U A) \cdot L M T D=\frac{A \cdot L M T D}{\left\{\frac{1}{h_{\mathrm{w}} A}+R_{\mathrm{p}}+\frac{1}{h_{\mathrm{r}} A}\right\}}
$$

where the heat transfer rate, $Q_{w}$, is determined from the HTF. The log-mean temperature difference is LMTD, $R_{\mathrm{p}}$ is the resistance of the plate, A is the total heat transfer area, and $h_{\mathrm{w}}$ and $h_{\mathrm{r}}$ are the heat transfer coefficients for the HTF and refrigerant, respectively.

The HTF heat transfer rate $\left(Q_{\mathrm{w}}\right)$ for the evaporator (ev) and condenser (co) is calculated as:

$$
\begin{aligned}
& Q_{\mathrm{w}, \mathrm{ev}}=m_{\mathrm{w}, \mathrm{ev}} c_{\mathrm{p}, \mathrm{w}}\left(T_{\mathrm{w}, \mathrm{ev}, \mathrm{in}}-T_{\mathrm{w}, \mathrm{ev}, \mathrm{out}}\right) \\
& Q_{\mathrm{w}, \mathrm{co}}=m_{\mathrm{w}, \mathrm{co}} c_{\mathrm{p}, \mathrm{w}}\left(T_{\mathrm{w}, \mathrm{co}, \mathrm{out}}-T_{\mathrm{w}, \mathrm{co}, \mathrm{in}}\right)
\end{aligned}
$$


where $m_{\mathrm{w}}$ is the HTF mass flow rate and $c_{\mathrm{p}}$ is the HTF specific heat.

The heat transfer rate for the refrigerant $\left(Q_{\mathrm{r}}\right)$ is:

$$
\begin{aligned}
& Q_{\mathrm{r}, \mathrm{ev}}=m_{\mathrm{r}}\left(i_{\mathrm{r}, \mathrm{ev}, \text { out }}-i_{\mathrm{r}, \text { ev }, \text { in }}\right) \\
& Q_{\mathrm{r}, \mathrm{co}}=m_{\mathrm{r}}\left(i_{\mathrm{r}, \mathrm{co}, \text { in }}-i_{\mathrm{r}, \mathrm{co}, \text { out }}\right)
\end{aligned}
$$

where $m_{\mathrm{r}}$ is the refrigerant flow rate and $i$ represents enthalpy. The inlet refrigerant enthalpy, $i_{\mathrm{r}, \mathrm{in}}$, was assumed to be equal to the refrigerant enthalpy entering the expansion valve. Table 3 summarizes the variation in heat transfer rates as calculated using refrigerant and glycol properties for each refrigerant in both the evaporator and condenser. The relative difference in heat transfer rates is determined from the expression:

$$
\% \text { difference }=\frac{\left( \pm Q_{\mathrm{w}} \mp Q_{\mathrm{r}}\right) \cdot 100}{Q_{\mathrm{w}}}
$$

where the upper signs are for the evaporator and the lower signs are for the condenser.

Table 3: Average relative difference (\%) in calculated heat transfer rates for refrigerants and HTF.

\begin{tabular}{||l||c|c||c|c||}
\hline \multirow{2}{*}{ Refrigerant } & \multicolumn{2}{c|}{ Evaporator } & \multicolumn{2}{c||}{ Condenser } \\
\cline { 2 - 5 } & Heating mode & Cooling mode & Heating mode & Cooling mode \\
\hline \hline R22 & 2.1 & -1.5 & -1.1 & -3.1 \\
\hline R290 & 2.0 & -0.4 & -2.0 & -0.8 \\
\hline R290/600a & -6.7 & -3.5 & 2.4 & 1.3 \\
\hline R32/152a & 18 & 5.8 & -16 & -5.9 \\
\hline
\end{tabular}

The average magnitude of the difference in heat transfer rates between the HTF and refrigerant is less than $18 \%$ in all cases. The uncertainties seen with the mixtures in Table 3 are most likely due to the refrigerant properties as calculated by REFPROP. This is evidenced by the less than $5 \%$ disagreement in the energy balance seen with the pure fluids. The correlations were developed using the water-side heat flux which was measured with less uncertainty that the refrigerant-side.

The log-mean temperature difference, $L M T D$, used in Eqn. 9 is for the entire heat exchanger and is determined from a weighted average of the LMTDs for each segment of the heat exchanger; superheat, two-phase, and subcooled (Kedzierski, 1997): 


$$
\begin{aligned}
& L M T D_{\mathrm{ev}}=\frac{Q_{\mathrm{HTF}}}{\frac{Q_{\mathrm{HTF}, \mathrm{ev}, \mathrm{sh}}}{L M T D_{\mathrm{HTF}, \mathrm{ev}, \mathrm{sh}}}+\frac{Q_{\mathrm{HTF}, \mathrm{ev}, \mathrm{tp}}}{L M T D_{\mathrm{HTF}, \mathrm{ev}, \mathrm{tp}}}} \\
& L M T D_{\mathrm{co}}=\frac{Q_{\mathrm{HTF}}}{\frac{Q_{\mathrm{HTF}, \mathrm{co}, \mathrm{sh}}}{L M T D_{\mathrm{HTF}, \mathrm{co}, \mathrm{sh}}}+\frac{Q_{\mathrm{HTF}, \mathrm{co}, \mathrm{tp}}}{L M T D_{\mathrm{HTF}, \mathrm{co}, \mathrm{pp}}}+\frac{Q_{\mathrm{HTF}, \mathrm{co}, \mathrm{sh}}}{L M T D_{\mathrm{HTF}, \mathrm{co}, \mathrm{sh}}}}
\end{aligned}
$$

An alternate method for determining LMTD is to neglect the refrigerant subcooling and superheating and use the refrigerant saturation temperature instead of the actual refrigerant inlet and outlet temperatures in the expression for LMTD. This approach may be reasonable for cases with small percentages of the overall heat transfer occurring in the subcooled and superheated regions. The expressions for $L M T D$ in this case are:

$$
\begin{aligned}
& L M T D_{\mathrm{ev}}{ }^{\prime}=\frac{\left(T_{\mathrm{w}, \text { out }}-T_{\mathrm{r}, \text { in }}\right)_{\mathrm{ev}}-\left(T_{\mathrm{w}, \mathrm{in}}-T_{\mathrm{r}, \mathrm{sat}, \mathrm{out}}\right)_{\mathrm{ev}}}{\ln \left(\frac{T_{\mathrm{w}, \text { out }}-T_{\mathrm{r}, \mathrm{in}}}{T_{\mathrm{w}, \mathrm{in}}-T_{\mathrm{r}, \mathrm{sat}}}\right)_{\mathrm{ev}}} \\
& L M T D_{\mathrm{co}}{ }^{\prime}=\frac{\left(T_{\mathrm{w}, \text { in }}-T_{\mathrm{r}, \text { sat out }}\right)_{\mathrm{co}}-\left(T_{\mathrm{w}, \text { out }}-T_{\mathrm{r}, \text { satin }}\right)_{\mathrm{co}}}{\ln \left(\frac{T_{\mathrm{w}, \text { in }}-T_{\mathrm{r} \text {,sat,out }}}{T_{\mathrm{w}, \text { out }}-T_{\mathrm{r}, \text { sat, }, \text { in }}}\right)_{\mathrm{co}}}
\end{aligned}
$$

where $T_{\mathrm{r}, \text { in }}$ is the measured refrigerant inlet temperature and $T_{\mathrm{r}, \mathrm{sat}}$ is the saturation temperature of the refrigerant evaluated at the refrigerant pressure.

Comparison of the two definitions for LMTD shows that the relationship between heat transfer and weighted average LMTD (Eqn. 12) is more nearly linear for all but one refrigerant in one heat exchanger (R290/600a in the evaporator). Thus, the weighted average $L M T D$ is used to determine the heat transfer coefficient in this study.

The HTF heat transfer coefficient, $h_{\mathrm{w}}$, is determined from the liquid Nusselt number $\left(\mathrm{Nu}_{\mathrm{L}}\right)$ correlation development of Gasche (1998):

$$
\begin{gathered}
\mathrm{Nu}_{\mathrm{L}}=0.16 \operatorname{Re}_{\mathrm{L}}^{0.89} \operatorname{Pr}_{\mathrm{L}}^{0.3(0.4)} \\
h_{\mathrm{w}}=\mathrm{Nu}_{\mathrm{L}} k_{\mathrm{L}} / D
\end{gathered}
$$

where the exponent on the Prandtl number depends on whether the fluid is being heated (0.4) or cooled (0.3). Eqn. 14 differs in two ways from that developed by Gasche. First, several data points were inadvertently omitted from the statistical analysis used to determine the values for the constants in Gasche's work. These points are included in the determination of the constants for this work. Secondly, Eqn. 14 does not include the ratio 
of bulk fluid viscosity to viscosity at the plate surface temperature which Gasche included. The constants in the correlation were determined with and without the viscosity ratio term and were found to be identical in both cases. Thus, the viscosity ratio term has no influence on the heat transfer coefficient and is not included in the correlation for simplicity.

The energy balance of Eqn. 9 was solved for the refrigerant heat transfer coefficient, $h_{\mathrm{r}}$, and the refrigerant Nusselt number was determined from the expression:

$$
\mathrm{Nu}=\frac{h_{\mathrm{r}} D}{k_{\mathrm{L}}}
$$

\section{Uncertainty analysis}

Before any correlations were considered, data points with expanded relative uncertainty (95\% confidence level) of the two-phase Nusselt number greater than $50 \%$ were removed. For the evaporator, this resulted in the removal of just five points, all of them for R290. For the condenser, five points were removed, three for R22 and two for R290. Data points for which $L M T D$ was undefined due to a negative temperature difference in the natural $\log$ term were also eliminated. The negative temperature difference resulted because the uncertainty in the temperature measurement was greater than the actual temperature difference between the fluids. This affected only R290 in the condenser, requiring the removal of four additional data points. After the removal of data due to the Nusselt number uncertainty criteria, LMTD criteria, and statistical analyses, the average expanded relative uncertainties were determined for the primary calculated parameters and are provided in Tables 4 and 5 .

Table 4. Average expanded relative uncertainties (95\% confidence level) for the evaporator.

\begin{tabular}{||c||c|c|c|c|c|c|c|c||}
\hline \multirow{2}{*}{ Parameter } & \multicolumn{9}{|c||}{ UNCERTAINTY (\%) } \\
\cline { 2 - 9 } & \multicolumn{2}{|c|}{ R22 } & \multicolumn{2}{c|}{ R290 } & \multicolumn{2}{c||}{ R290/600a } & \multicolumn{2}{c||}{ R32/152a } \\
\cline { 2 - 9 } & heat & cool & heat & cool & heat & cool & heat & cool \\
\hline \hline$h_{\mathrm{r}}$ & 25 & 12 & 21 & 15 & 19 & 15 & 9.9 & 9.0 \\
\hline$L M T D$ & 11 & 6.1 & 9.2 & 7.5 & 9.0 & 8.4 & 7.0 & 4.7 \\
\hline$m_{\mathrm{r}}$ & 0.08 & 0.08 & 0.08 & 0.08 & 0.07 & 0.07 & 0.09 & 0.08 \\
\hline $\mathrm{Nu}_{\mathrm{L}}{ }^{*}$ & 17 & 17 & 17 & 17 & 17 & 17 & 17 & 17 \\
\hline $\mathrm{Nu}_{\mathrm{r}}$ & 25 & 12 & 21 & 15 & 19 & 15 & 9.9 & 9.0 \\
\hline$Q_{\mathrm{r}}$ & 0.2 & 0.2 & 0.3 & 0.3 & 0.3 & 0.3 & 0.2 & 0.2 \\
\hline$Q_{\mathrm{w}}$ & 11 & 6.0 & 11 & 6.1 & 11 & 6.1 & 12 & 6.1 \\
\hline $\mathrm{Re}_{\mathrm{L}}$ & 1.2 & 1.1 & 1.1 & 1.1 & 1.1 & 1.1 & 1.2 & 1.1 \\
\hline
\end{tabular}

- estimated from Gasche (1998) 
Table 5. Average expanded relative uncertainties ( $95 \%$ confidence level) for the condenser.

\begin{tabular}{||c||c|c|c|c|c|c|c|c||}
\hline \multirow{2}{*}{} & \multicolumn{9}{c||}{ UNCERTAINTY (\%) } \\
\cline { 2 - 10 } Parameter & \multicolumn{2}{|c|}{ R22 } & \multicolumn{2}{c|}{ R290 } & \multicolumn{2}{c||}{ R290/600a } & \multicolumn{2}{c||}{ R32/152a } \\
\cline { 2 - 10 } & heat & cool & heat & cool & heat & cool & heat & cool \\
\hline \hline$h_{\mathrm{r}}$ & 30 & 13 & 18 & 14 & 5.8 & 7.8 & 10 & 9.6 \\
\hline$L M T D$ & 9.4 & 4.8 & 7.4 & 5.3 & 5.9 & 3.9 & 6.4 & 3.4 \\
\hline$m_{\mathrm{r}}$ & 0.09 & 0.08 & 0.08 & 0.08 & 0.07 & 0.07 & 0.09 & 0.08 \\
\hline $\mathrm{Nu}_{\mathrm{L}}{ }^{*}$ & 17 & 17 & 17 & 17 & 17 & 17 & 17 & 17 \\
\hline $\mathrm{Nu}_{\mathrm{r}}$ & 30 & 13 & 18 & 14 & 5.8 & 7.9 & 11 & 9.7 \\
\hline$Q_{\mathrm{r}}$ & 0.20 & 0.20 & 0.25 & 0.25 & 0.24 & 0.24 & 0.19 & 0.19 \\
\hline$Q_{\mathrm{w}}$ & 8.0 & 6.1 & 7.9 & 6.2 & 7.3 & 6.2 & 9.3 & 6.1 \\
\hline $\mathrm{Re}_{\mathrm{L}}$ & 1.2 & 1.2 & 1.2 & 1.2 & 1.2 & 1.2 & 1.2 & 1.2 \\
\hline
\end{tabular}

- estimated from Gasche (1998)

\section{CORRELATIONS}

The heat and mass flux ranges for the evaporator and condenser correlations in the literature that were considered as comparisons for this study are shown as shaded regions in Figures 1 and 2. These illustrations, similar to that used by Smith et al. (1993), also contain regions covering the heat and mass flux ranges for the data of this study. As seen from the figures, the heat and mass fluxes for this study are generally lower than those for the studies in the literature. Only the Shah evaporator correlation has any overlap with the data considered here. Thus, it is not expected that any of the correlations will fit the present data well, as seen for R22 in Figures 5 and 6 which show the two-phase Nusselt number predicted by various correlations versus the two-phase Nusselt number determined from the data for this study. Very few of the two-phase Nusselt numbers from the correlations are within $25 \%$ of the calculated Nusselt numbers.

In addition to examining the accuracy of using correlations from the literature for the data of this study, the behavior trends for the refrigerants in this study were compared with one another. Two distinct data trends are noticeable in Figure 7, a plot of the two-phase Nusselt number versus the liquid refrigerant Reynolds number for the evaporator. The liquid refrigerant Reynolds number is determined using the mass flux $(G)$ for the liquid portion of the flow $(1-\bar{x})$ :

$$
\operatorname{Re}_{L}=\frac{G(1-\bar{x}) D}{\mu_{L}}
$$

If a distinct curve could be seen in Figure 7 for each refrigerant, the correlation of the Nusselt number using solely Reynolds and Prandtl numbers would be suggested. Use of the Prandtl number might collapse all curves into one. This is not the case for the data in 
Figure 7. The R32/152a data has distinctly lower Nusselt numbers at given Reynolds numbers than the data for the other refrigerants. This is likely attributable to the fact that R32/152a used a different lubricant than the other refrigerants. Mineral oil was used with all refrigerants except R32/152a which used a polyol ester oil (POE). The use of a different lubricant was necessary due to immiscibility and poor oil return in R32/152a. By using a POE with $\mathrm{R} 32 / 152 \mathrm{a}$, oil/ refrigerant miscibility was obtained. The distinctly different behavior of R32/152a from the other refrigerants shown in Figure 7 is accommodated by developing a correlation for it separate from the correlation developed for the combined data of R22, R290, and R290/600a. The difference between R32/152a and the other refrigerants is not as distinct in the condenser as it is in the evaporator (see Figure 8). However, the difference is statistically significant and, thus, indicated the need for separate condenser correlations.

In all, 13 evaporator and 6 condenser correlation forms were selected from those in the literature for examination in this study. The forms of the correlations are provided in Tables 6 and 7. Some correlations, e.g, those of Shah and Traviss, were developed by combining dimensionless parameters from the literature correlations in formats that could be linearized. The Guo correlation does not contain the Jacob number because the wall temperature is not known for the data in this study. In some cases, the exponents on $\mathrm{Nu}_{\mathrm{L}}$, $\mathrm{Re}_{\mathrm{L}}$, and $\mathrm{Pr}_{\mathrm{L}}$ were not determined by statistical analysis but were pre-set to values typically found in the literature. All correlations considered, except Pierre's, contain either $\operatorname{Re}_{\mathrm{L}}$ and $\operatorname{Pr}_{\mathrm{L}}$ or $\mathrm{Nu}_{\mathrm{L}}$ because $\mathrm{Nu}_{\mathrm{L}}$ is itself a function of $\mathrm{Re}_{\mathrm{L}}$ and $\operatorname{Pr}_{\mathrm{L}}$ as shown in Eqn. 14. 
Table 6. Evaporator correlation formats analyzed.

\begin{tabular}{|c|c|c|}
\hline No. & Form & Source \\
\hline 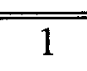 & $\mathrm{Nu}_{\mathrm{r}}=\mathrm{a} \operatorname{Re}_{\mathrm{L}}^{\mathrm{b}} \mathrm{Pr}_{\mathrm{L}}^{\mathrm{c}} \mathrm{Bo}^{\mathrm{d}} \omega^{\mathrm{e}}$ & $\overline{\text { Kedzierski (1998) }}$ \\
\hline 2 & $\mathrm{Nu}_{\mathrm{r}}=\mathrm{aRe} \mathrm{Re}_{10}{ }^{\mathrm{b}} \mathrm{K}^{\mathrm{c}}$ & Pierre (1956) \\
\hline 3 & 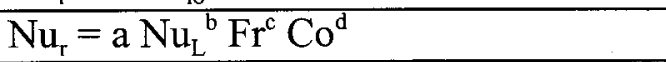 & Shah (1982) \\
\hline$\overline{4}$ & $\mathrm{Nu}_{\mathrm{r}}=\mathrm{a} \mathrm{Nu}_{\mathrm{L}}^{\mathrm{b}} \mathrm{Fr}^{\mathrm{c}} \mathrm{Co}^{\mathrm{d}} \quad(\mathrm{b}=1)$ & Shah (1982) \\
\hline 5 & 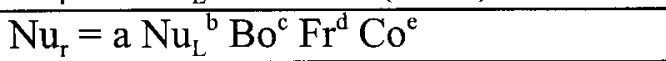 & variation of Shah \\
\hline 6 & 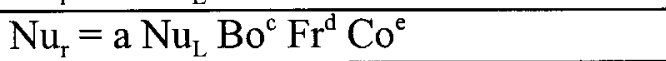 & variation of Shah \\
\hline 7 & 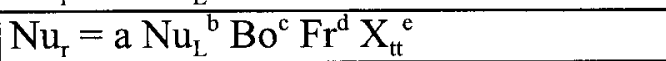 & Smith (1993) \\
\hline 8 & $\mathrm{Nu}_{\mathrm{r}}=\mathrm{a} \mathrm{Nu} \mathrm{Bu}_{\mathrm{L}} \mathrm{Bo}^{\mathrm{c}} \mathrm{Fr}^{\mathrm{d}} \mathrm{X}_{\mathrm{tt}}^{\mathrm{e}}$ & Smith (1993) \\
\hline 9 & $\mathrm{Nu}_{\mathrm{r}}=\mathrm{a} \mathrm{Nu}_{\mathrm{L}}^{\mathrm{b}} \mathrm{Bo}^{\mathrm{c}} \mathrm{Fr}^{\mathrm{d}} \omega^{\mathrm{e}} \mathrm{Co}^{\mathrm{f}} \mathrm{X}_{\mathrm{tt}}^{\mathrm{g}} M^{\mathrm{h}}$ & combination of $1-8$ \\
\hline 10 & $\mathrm{Nu}_{\mathrm{r}}=\mathrm{a} \mathrm{Nu_{ \textrm {L } }} \mathrm{Bo}^{\mathrm{c}} \mathrm{Fr}^{\mathrm{d}} \omega^{\mathrm{e}} \mathrm{Co}^{\mathrm{f}} X_{\mathrm{tt}}^{\mathrm{g}} M^{\mathrm{h}}$ & combination of $1-8$ \\
\hline 11 & $\mathrm{Nu}_{\mathrm{r}}=\mathrm{a} \mathrm{Re}_{\mathrm{L}}{ }^{\mathrm{b}} \mathrm{Pr}_{\mathrm{L}}^{\mathrm{c}} \mathrm{Bo}^{\mathrm{d}} \omega^{\mathrm{e}} \mathrm{Fr}^{\mathrm{f}} \mathrm{Co}^{\mathrm{g}} \mathrm{X}_{\mathrm{tt}}^{\mathrm{h}}$ & combination of $1-8$ \\
\hline 12 & $\mathrm{Nu}_{\mathrm{r}}=\mathrm{a} \operatorname{Re}_{\mathrm{L}}^{0.8} \mathrm{Pr}_{\mathrm{L}}^{0.4} \mathrm{Bo}^{\mathrm{d}} \omega^{\mathrm{e}} \mathrm{Fr}^{\mathrm{f}} \mathrm{Co}^{\mathrm{g}} \mathrm{X}_{\mathrm{tt}}^{\mathrm{h}}$ & combination of $1-8$ \\
\hline 13 & $\mathrm{Nu}_{\mathrm{r}}=\mathrm{a} \operatorname{Re}_{\mathrm{L}}{ }^{\mathrm{b}} \mathrm{Pr}_{\mathrm{L}}{ }^{0.4} \mathrm{Bo}^{\mathrm{d}} \omega^{\mathrm{e}} \mathrm{Fr}^{\mathrm{f}} \mathrm{Co}^{\mathrm{g}} \mathrm{X}_{\mathrm{tt}}^{\mathrm{h}}$ & combination of $1-8$ \\
\hline
\end{tabular}

Table 7. Condenser correlation formats analyzed.

\begin{tabular}{|c|c|c|}
\hline No. & Form & Source \\
\hline 1 & $\mathrm{Nu}_{\mathrm{r}}=\mathrm{a} \phi_{\mathrm{I}}^{\mathrm{b}} \mathrm{Re}_{\mathrm{I}}^{\mathrm{c}} \operatorname{Pr}_{\mathrm{I}}^{\mathrm{d}} \mathrm{Ga}^{\mathrm{e}}$ & Guo (1999) \\
\hline 2 & $\mathrm{Nu}_{\mathrm{r}}=\mathrm{a} \operatorname{Re}_{\mathrm{L}}^{\mathrm{b}} \operatorname{Pr}_{\mathrm{L}}^{\mathrm{c}} X_{\mathrm{tt}}^{\mathrm{d}}$ & Traviss (1973) \\
\hline 3 & $\mathrm{Nu}_{\mathrm{r}}=\mathrm{a} \mathrm{Nu_{ \textrm {L } } ^ { \mathrm { b } }} P_{\mathrm{red}}^{\mathrm{c}}$ & Shah (1979) \\
\hline 4 & $\mathrm{Nu}_{\mathrm{r}}=\mathrm{a} \operatorname{Re}_{\mathrm{L}}^{\mathrm{b}} \operatorname{Pr}_{\mathrm{L}}^{\mathrm{c}} P_{\text {red }}^{\mathrm{d}} \omega^{\mathrm{e}}$ & Kedzierski (1998) \\
\hline 5 & $\mathrm{Nu}_{\mathrm{r}}=\mathrm{a} \mathrm{Nu}_{\mathrm{L}}^{\mathrm{b}} \phi_{\mathrm{L}}^{\mathrm{c}} \mathrm{Ga}^{\mathrm{d}} X_{\mathrm{tt}}^{\mathrm{e}} P_{\mathrm{red}}{ }^{\mathrm{f}} \omega^{\mathrm{g}}$ & combination of 1-4 \\
\hline 6 & $\mathrm{Nu}_{\mathrm{r}}=\mathrm{a} \operatorname{Re}_{\mathrm{L}}{ }^{\mathrm{b}} \operatorname{Pr}_{\mathrm{L}}{ }^{\mathrm{c}} \phi_{\mathrm{L}}{ }^{\mathrm{d}} \mathrm{Ga}^{\mathrm{e}} X_{\mathrm{tt}}^{\mathrm{f}} P_{\mathrm{red}}{ }^{\mathrm{g}} \omega^{\mathrm{h}}$ & combination of 1-4 \\
\hline
\end{tabular}

The correlation forms considered in this study were chosen for the dimensionless parameters they employed and for their ease of linearization. The linearization characteristic was necessary in order that statistical analysis tools for linear functions could be employed to their fullest capacity. For example, correlation 1 in Table 6 and its linearized counterpart are:

$$
\begin{gathered}
\mathrm{Nu}_{\mathrm{r}}=\mathrm{a} \operatorname{Re}_{\mathrm{L}}^{\mathrm{b}} \operatorname{Pr}_{\mathrm{L}}^{\mathrm{c}} \mathrm{Bo}^{\mathrm{d}} \omega^{\mathrm{e}} \\
\ln \left(\mathrm{Nu}_{\mathrm{r}}\right)=\ln \mathrm{a}+\mathrm{b} \ln \operatorname{Re}_{\mathrm{L}}+\mathrm{c} \ln \operatorname{Pr}_{\mathrm{L}}+\mathrm{d} \ln \mathrm{Bo}+\mathrm{e} \ln \omega
\end{gathered}
$$

The possible dimensionless parameters that influence the two-phase Nusselt number for the BPHE are selected from those used in correlations for similar flow regimes in the literature. Where needed, the correlation for the HTF heat transfer coefficient, Eqn. 14, is used for the refrigerant liquid-phase Nusselt number, $\mathrm{Nu}_{\mathrm{L}}$.

As mentioned previously, two correlations were developed for each heat exchanger, one for the combined data of R22, R290, and R290/600a and one for R32/152a. The 
constants in each correlation were determined using statistical analysis software. After the constants were found for all correlations, the best correlation was chosen as the one for which the standard deviation of the residuals was a minimum. In the process of developing each correlation, only those terms in the correlation deemed to be statistically significant were retained. After ensuring that all terms in the correlation were significant, data points were removed from the data set if they were determined to be highly influential or outliers. Originally, 131 data sets were considered for R22, R290, and R290/600a. After elimination of data due to high Nusselt number uncertainty, undefined LMTD, and poor statistics, 106 data points were used for the evaporator correlation and 107 data points were used for the condenser correlation. Because the original data set for R32/152a was small (20 points) and none of the points had high Nusselt number uncertainty or undefined $L M T D$, all data points were retained in examining all correlations for the evaporator and condenser.

\section{RESULTS}

\section{Evaporator}

The evaporator correlation for R22, R290, and R290/600a results from correlation number 1 in Table 6:

$$
\mathrm{Nu}_{\mathrm{r}}=\mathrm{aRe}_{\mathrm{L}}^{\mathrm{b}} \operatorname{Pr}_{\mathrm{L}}^{\mathrm{c}} \mathrm{Bo}^{\mathrm{d}} \omega^{\mathrm{e}}
$$

The values for the constants in the final correlations are provided in Table 8. Figure 9 is a graph of $\mathrm{Nu}_{\mathrm{r}}$ calculated from the data versus $\mathrm{Nu}_{\mathrm{r}}$ determined from the correlation for R22, R290, and R290/600a. Lines for the mean and $\pm 25 \%$ tolerance are shown on the figure, revealing that Eqn. 18 correlates $65 \%$ of the data within approximately $\pm 25 \%$.

The evaporator correlation for $\mathrm{R} 32 / 152 \mathrm{a}$ results from correlation number 9 in Table 6:

$$
\mathrm{Nu}_{\mathrm{r}}=\mathrm{aNu} \mathrm{L}_{\mathrm{b}}^{\mathrm{b}} \mathrm{Bo}^{\mathrm{c}} \mathrm{Fr}^{\mathrm{d}} \omega^{\mathrm{e}} \mathrm{Co}^{\mathrm{f}} \mathrm{X}_{\mathrm{tt}}^{\mathrm{g}} \mathrm{M}^{\mathrm{h}}
$$

The values for the constants in Eqn. 19 are provided in Table 8. Figure 10 shows the relationship between calculated and correlated $\mathrm{Nu}_{\mathrm{r}}$ for $\mathrm{R} 32 / 152 \mathrm{a}$. Eqn. 19 correlates $100 \%$ of the data within $\pm 25 \%$.

Table 8. Values for evaporator correlation constants.

\begin{tabular}{|c|c|c||}
\hline \hline constant & $\begin{array}{c}\text { R22, R290, and R290/600a } \\
\text { (Eqn. 18) }\end{array}$ & $\begin{array}{c}\text { R32/152a } \\
\text { (Eqn. 19) }\end{array}$ \\
\hline \hline $\mathrm{a}$ & 2.7 & 1 \\
\hline $\mathrm{b}$ & 0.55 & 0.42 \\
\hline $\mathrm{c}$ & 0.50 & 0 \\
\hline $\mathrm{d}$ & 0 & 0.088 \\
\hline $\mathrm{e}$ & 0 & 1.5 \\
\hline $\mathrm{f}$ & - & 1.5 \\
\hline $\mathrm{g}$ & - & 0 \\
\hline $\mathrm{h}$ & - & 1.5 \\
\hline
\end{tabular}




\section{Condenser}

The condenser correlations for R22, R290, and R290/600a and R32/152a both result from correlation number 5 in Table 7:

$$
\mathrm{Nu}_{\mathrm{r}}=\mathrm{aNu}_{\mathrm{L}}^{\mathrm{b}} \phi_{\mathrm{L}}^{\mathrm{c}} \mathrm{Ga}^{\mathrm{d}} \mathrm{X}_{\mathrm{tt}}^{\mathrm{e}} \mathrm{P}_{\text {red }}^{\mathrm{f}} \omega^{\mathrm{g}}
$$

The values for the constants in the condenser correlations are provided in Table 9.

Table 9. Values for condenser correlation constants.

\begin{tabular}{||c|c|c||}
\hline constant & R22, R290, and R290/600a & R32/152a \\
\hline \hline $\mathrm{a}$ & 1 & 1 \\
\hline $\mathrm{b}$ & 0.387 & 0.298 \\
\hline $\mathrm{c}$ & 0.0824 & 0 \\
\hline $\mathrm{d}$ & 0.346 & 0.346 \\
\hline $\mathrm{e}$ & 0 & 0 \\
\hline $\mathrm{f}$ & 1.5 & 1.5 \\
\hline $\mathrm{g}$ & 1.5 & 1.5 \\
\hline
\end{tabular}

Figure 11 is a graph of the $\mathrm{Nu}_{\mathrm{r}}$ calculated from the data versus the $\mathrm{Nu}_{\mathrm{r}}$ determined from the correlation for R22, R290, and R290/600a. Lines for the mean and $\pm 25 \%$ tolerance are shown on the figure and Eqn. 20 correlates $90 \%$ of the data within $\pm 25 \%$. Figure 12 provides this same information for R32/152a where Eqn. 20 correlates $80 \%$ of the data within $\pm 25 \%$.

\section{CONCLUSIONS}

Average evaporation and condensation heat transfer correlations were developed for low heat and mass fluxes for R22, R290, and R290/600a as well as for R32/152a in BPHEs. The need for separate correlations may be attributable to the use of difference lubricants for the refrigerants; mineral oil was used with R22, R290, and R290/600a, and POE was used with R32/152a.

The accuracy of the data used in this study, as shown in Tables 4 and 5, and the resulting correlations reflect the fact that data were acquired as part of a study of overall WWHP performance. The measurements made in this study are typical of those taken during actual system operations and, thus, allow the correlations developed to be used in actual system design. It is important to note that the Reynolds numbers of this study were lower than shown for any of the referenced data taken by other investigators. This study has filled a low Reynolds number gap and also shown the importance of accurate refrigerant properties for refrigerant mixtures having very different dipole moments. 


\section{ACKNOWLEDGMENTS}

This work was jointly funded by NIST, the United States Naval Academy Research Council and the US Department of Energy (project no. DE-AI01-97EE23775), under manager Esher Kweller. The authors express their appreciation to Dr. Mark Kedzierski of NIST for his help in the statistical analysis of the data and to Lt. Cmdr. Dan Ray of the US Naval Academy for his thorough review of this work. 


\section{REFERENCES}

Baker, O., 1954, "Design of Pipe Lines for Simultaneous Flow of Oil and Gas," Oil and Gas, Vol. 52, July, 26.

Bansal, P.K., and B. Purkayastha, 1998, “An NTU-є Model for Alternative Refrigerants,” International Journal of Refrigeration, Vol. 21, No. 5, pp. 381-397.

Bogaert, R., and A. Bölcs, 1995, "Global Performance of a Prototype Brazed Plate Heat Exchanger in a Large Reynolds Number Range," Experimental Heat Transfer, Vol. 8, pp. 293-311.

Chitti, M.S., and N.K. Anand, 1996, "Condensation Heat Transfer Inside Smooth Horizontal Tubes for R-22 and R-32/ 125 Mixture," HVAC\&R Research, Vol. 2, No. 1, pp. 79-101.

Gasche, I., 1998, "Performance of a Brazed Plate Heat Exchanger and Development of a Nusselt-Correlation by Using a Wilson Plot Technique," M.S. Thesis, Fachhochschule Mannheim.

Guo, Z., and N.K. Anand, 1999, "Condensation of R-410A in a Rectangular Channel," HVAC\&R Research, Vol. 5, No. 2, pp. 99-123.

Incropera, F.P., and D.P. DeWitt, 1990, Fundamentals of Heat and Mass Transfer, Third Edition, New York, pp. 468-509.

Jung, D.S., McLinden, M., R. Radermacher, and D. Didion, 1989, "A Study of Flow Boiling Heat Transfer with Refrigerant Mixtures," International Journal of Heat and Mass Transfer, Vol. 32, No. 9, pp. 1751-1764.

Kandlikar, S.G., 1990, "A General Correlation for Saturated Two-Phase Flow Boiling Heat Transfer Inside Horizontal and Vertical Tubes," Journal of Heat Transfer, Vol. 112, pp. 219-228.

Kattan, N., J.R. Thome, and D. Favrat, 1998, "Flow Boiling in Horizontal Tubes: Part 3 Development of a New Heat Transfer Model Based on Flow Pattern," Journal of Heat Transfer, Vol. 120, pp. 156-165.

Kaushik, N., and N.Z. Azer, 1988, "A General Heat Transfer Correlation for Condensation Inside Internally Finned Tubes," ASHRAE Transactions, Vol. 94, Pt. 2, pp. 261-279.

Kays,W.M., and M.E. Crawford, 1980, Convective Heat and Mass Transfer, Second Edition, McGraw-Hill, New York, pp. 102-103. 
Kedzierski, M.A., 1997, "Effect of Inclination on the Performance of a Compact Brazed Plate Condenser and Evaporator," Heat Transfer Engineering, Vol. 18, No. 1, pp. 25-38.

Kedzierski, M.A., and M.S. Kim, 1998, "Convective Boiling and Condensation Heat Transfer with a Twisted-Tape Insert for R12, R22, R152a, R134a, R290, R32/R134a, R32/R152a, R290/R134a, R134a/R600a," Thermal Science and Engineering, Vol. 6, No. 1, pp. 113-122.

McLinden, M.O., S.A. Klein, E.W. Lemmon, and A.P., Peskin, 1998, REFPROP: NIST Standard Reference Database 23 - Version 6.0.

McLinden, M.O., 1999, Personal communications. National Institute of Standards and Technology. Boulder, CO.

Moffat, R.J., 1988, "Describing the Uncertainties in Experimental Results," Experimental Thermal and Fluid Sciences, Vol. 1, No. 1, pp. 3-17.

Panchal, C.B., 1984, "Heat Transfer with Phase Change in Plate-fin Heat Exchangers," AIChE Symposium Series, Vol. 80, No. 236, pp. 90-97.

Payne, W.V., P.A. Domanski, and J. Muller, 1999, "A Study of a Water-to-Water Heat Pump Using Hydrocarbon and Hydrofluorocarbon Zeotropic Mixtures," NISTIR 6330, National Institute of Standards and Technology, Gaithersburg, MD.

Pierre, B., 1956, "The Coefficient of Heat Transfer for Boiling Freon-12 in Horizontal Tubes," Heating and Air Treatment Engineer, December, pp. 302-310.

NIST, 1998, NIST thermodynamic properties of refrigerants and refrigerant mixtures database (REFPROP 6.01).

Shah, M.M., 1982, "Chart Correlation for Saturated Boiling Heat Transfer: Equations and Further Study," ASHRAE Transactions, Vol. 88, Pt. 1, pp. 185-196.

Shah, M.M., 1979, “A General Correlation for Heat Transfer During Film Condensation Inside Pipes," International Journal of Heat and Mass Transfer, Vol. 22, pp. 547-556.

Smith, M.K., J.P. Wattelet, and T.A. Newell, 1993, "A Study of Evaporation Heat Transfer Coefficient Correlations at Low Heat and Mass Fluxes for Pure Refrigerants and Refrigerant Mixtures," $29^{\text {th }}$ National Heat Transfer Conference of the ASME, Heat Transfer with Alternate Refrigerants, HTD-Vol. 243, pp. 19-26.

Soliman, M., J.R. Schuster, and P.J. Berenson, 1968, "A General Heat Transfer Correlation for Annular Flow Condensation," Journal of Heat Transfer, Transactions of the ASME, Vol. 90, No. 2, pp. 267-276. 
SWEP, n.d., Compact Brazed Heat Exchangers, Technical Data Sheet.

Thome, J.R., 1990, Enhanced Boiling Heat Transfer, Hemisphere Publishing Corporation, New York.

Thonon, B., A. Feldman, L. Margat, and C. Marvillet, 1997, "Transition from Nucleate Boiling to Convective Boiling in Compact Heat Exchangers," International Journal of Refrigeration, Vol. 20, No. 8, pp. 592-597.

Tinaut, F.V., A. Melgar, and A.A. Rahman Ali, 1992, "Correlations for Heat Transfer and Flow Friction Characteristics of Compact Plate-Type Heat Exchangers," International Journal of Heat and Mass Transfer, Vol. 35, No. 7, pp. 1659-1665.

Traviss, D.P., W.M. Rosenhow, and A.B. Baron, 1973, "Forced-Convection Condensation Inside Tubes: A Heat Transfer Equation for Condenser Design," ASHRAE Transactions, Vol. 79, Pt. 1, pp. 157-165. 


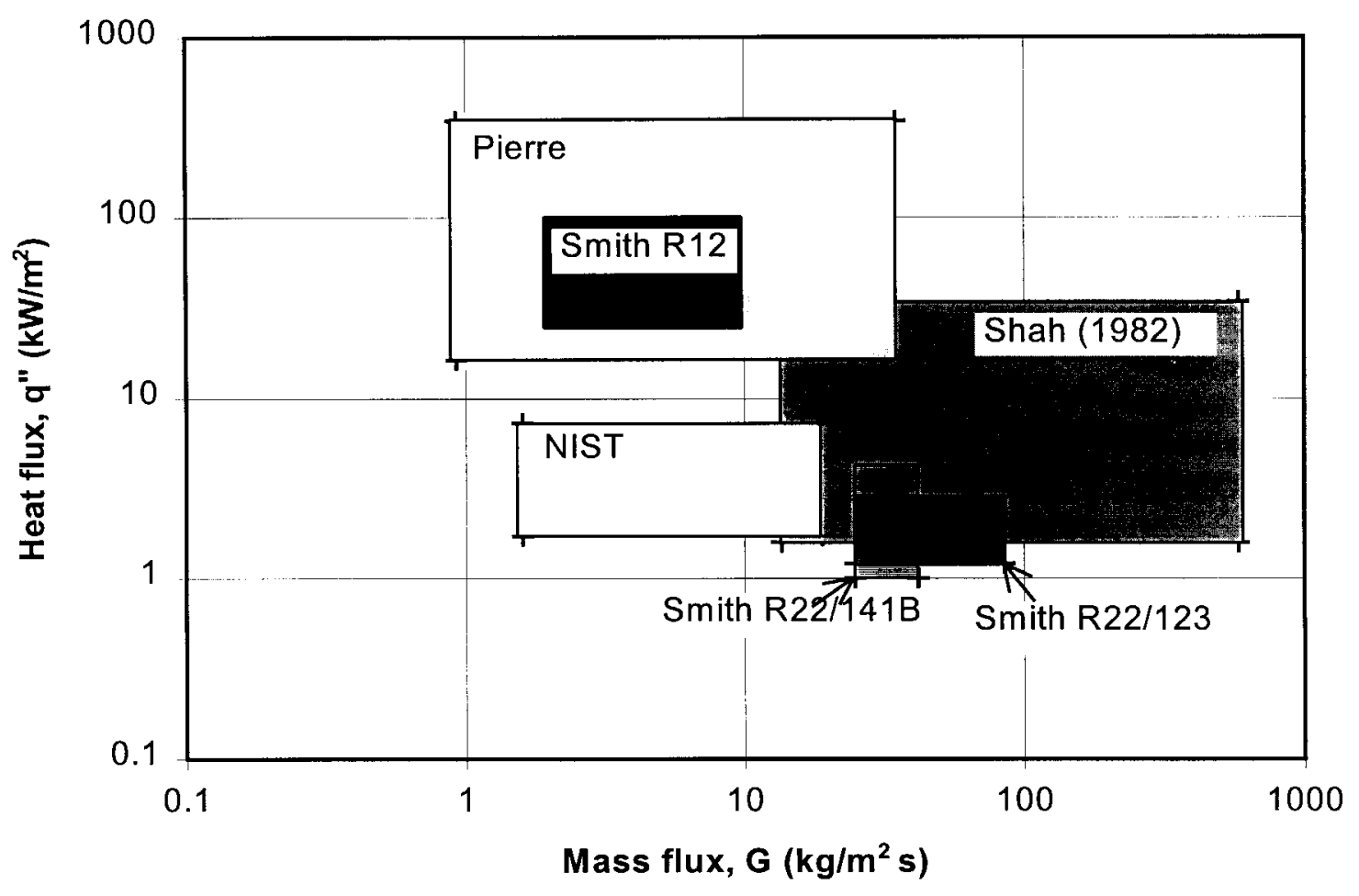

Figure 1. Heat and mass flux map for evaporator correlations of interest

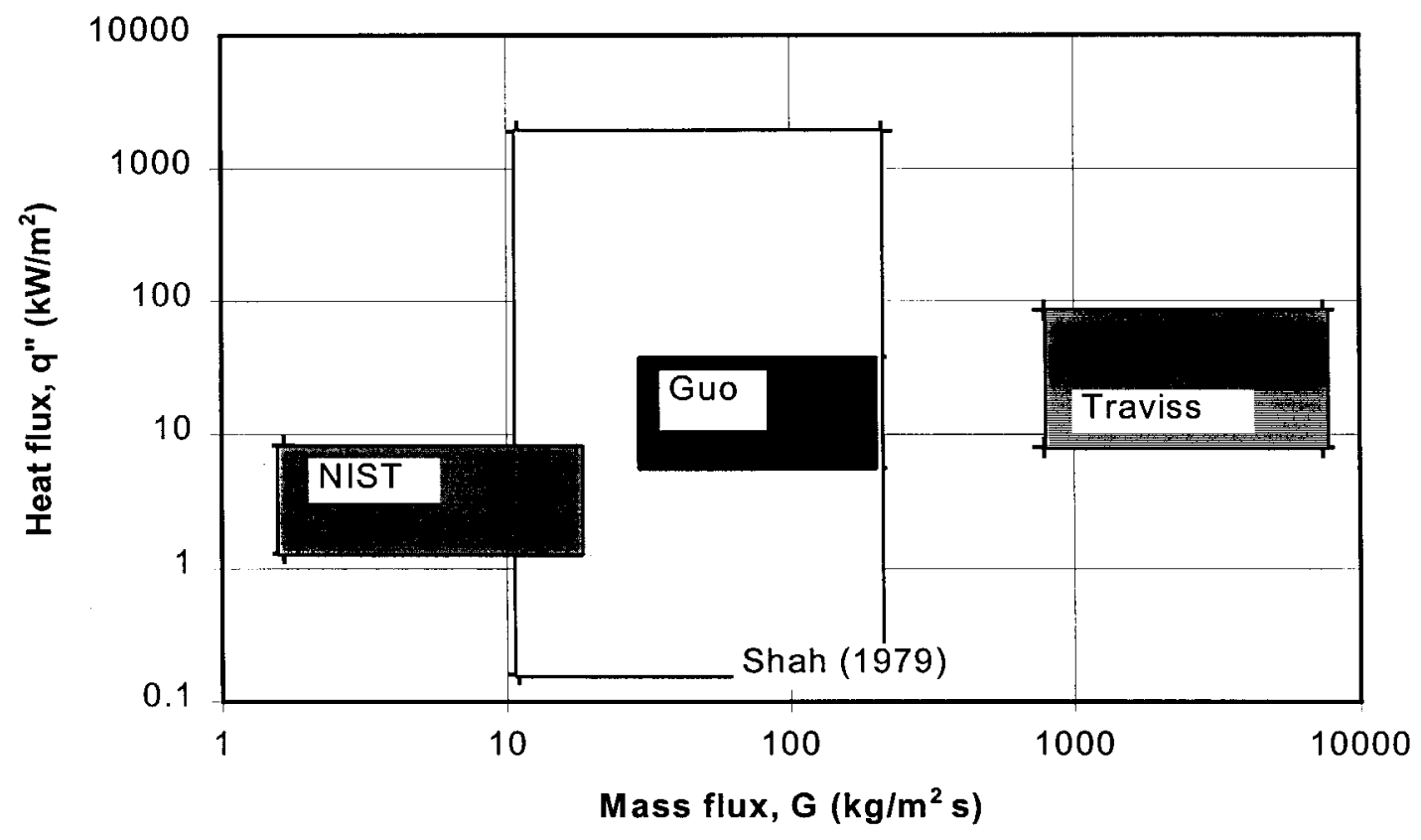

Figure 2. Heat and mass flux map for condenser correlations of interest. 


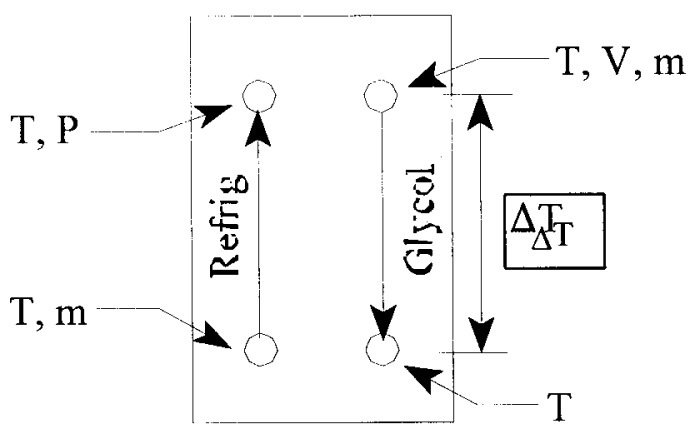

Figure 3. Evaporator schematic.

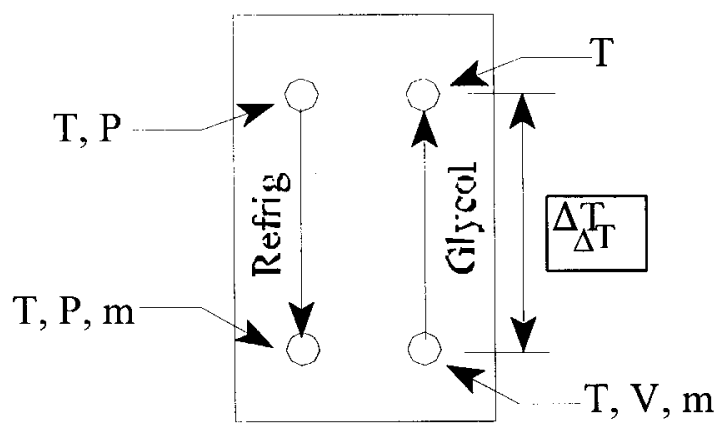

Figure 4. Condenser schematic. 


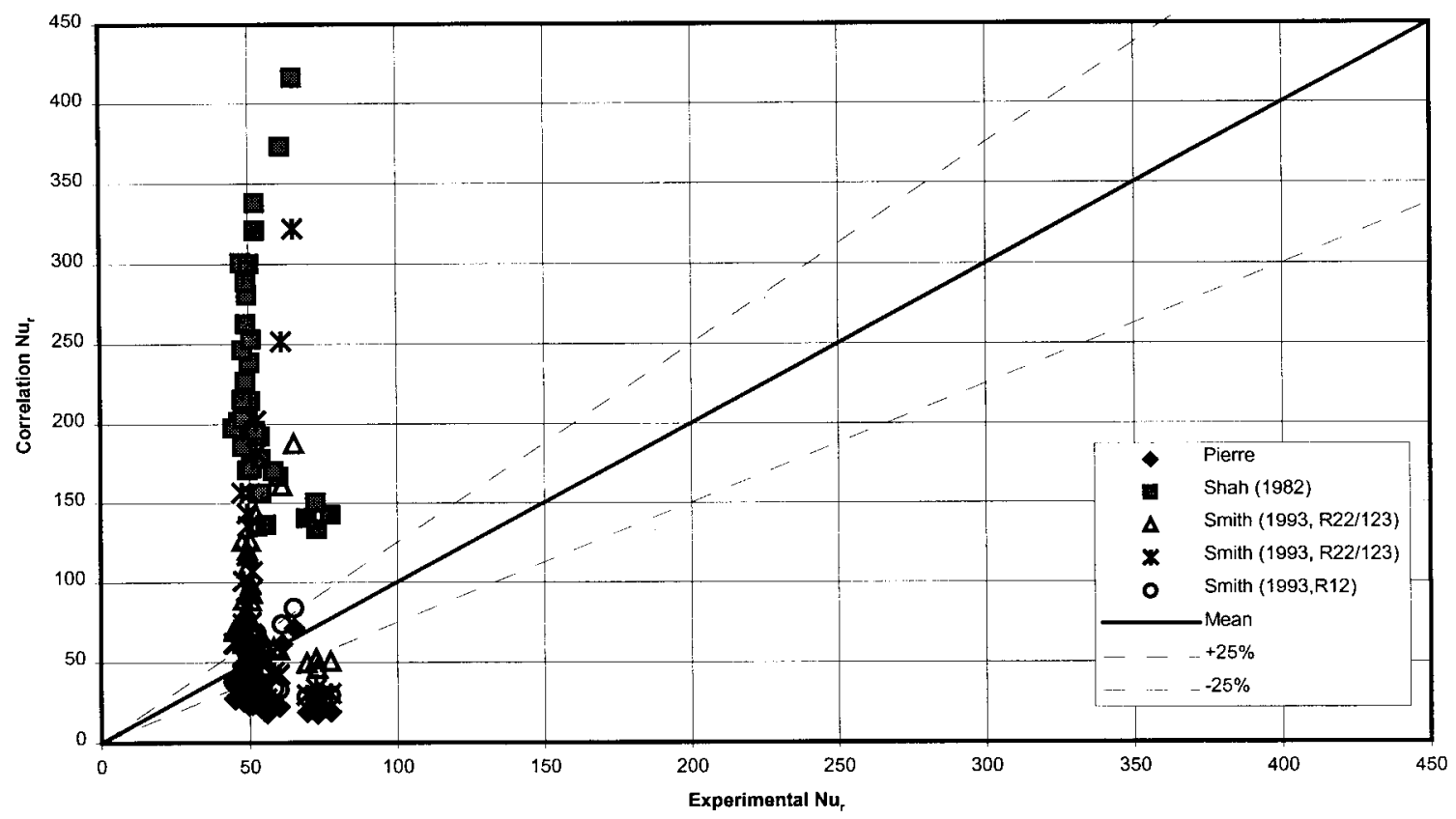

Figure 5. Comparison of correlations from literature to current evaporator study.

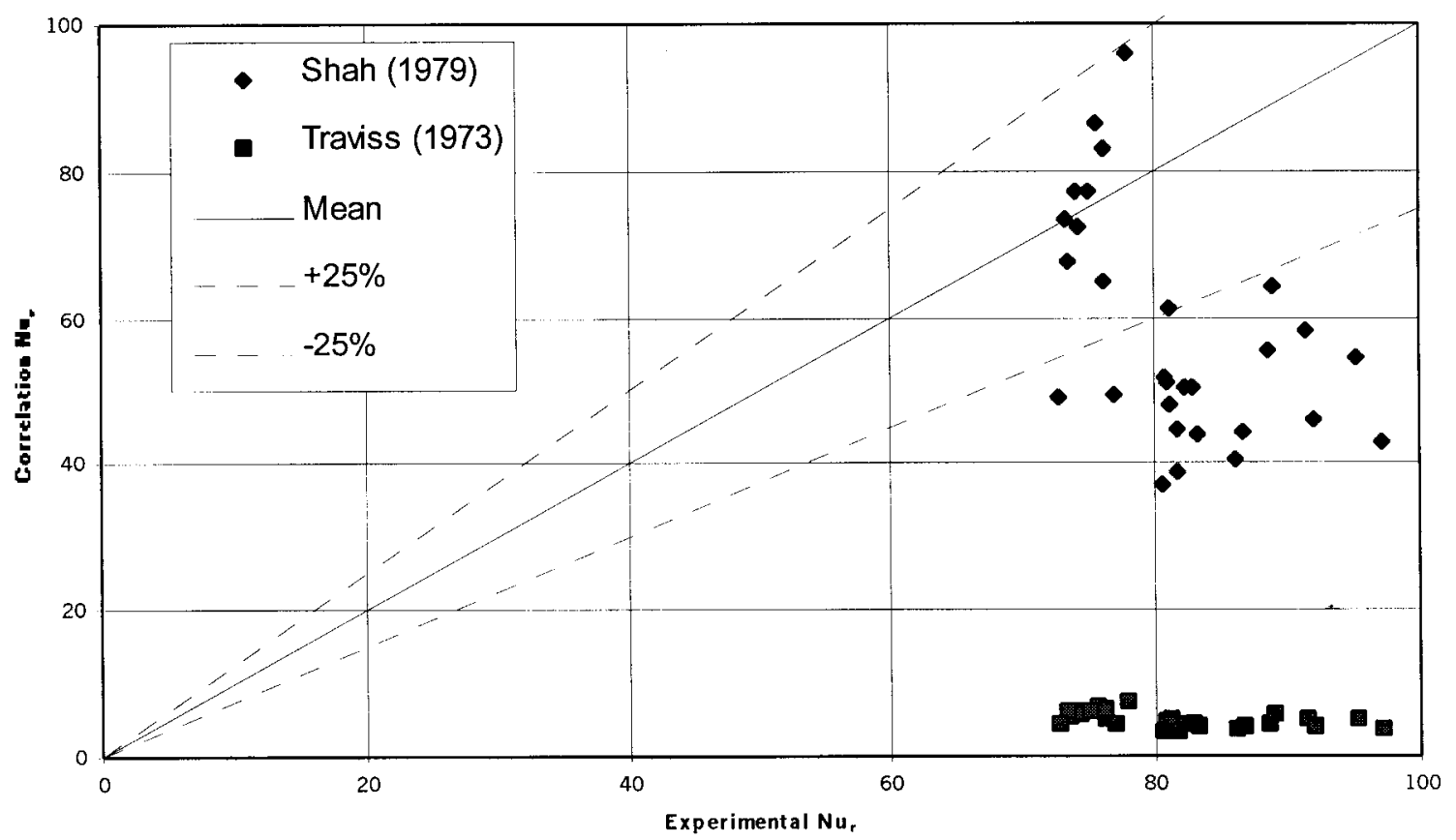

Figure 6. Comparison of correlations from literature to current condenser study. 


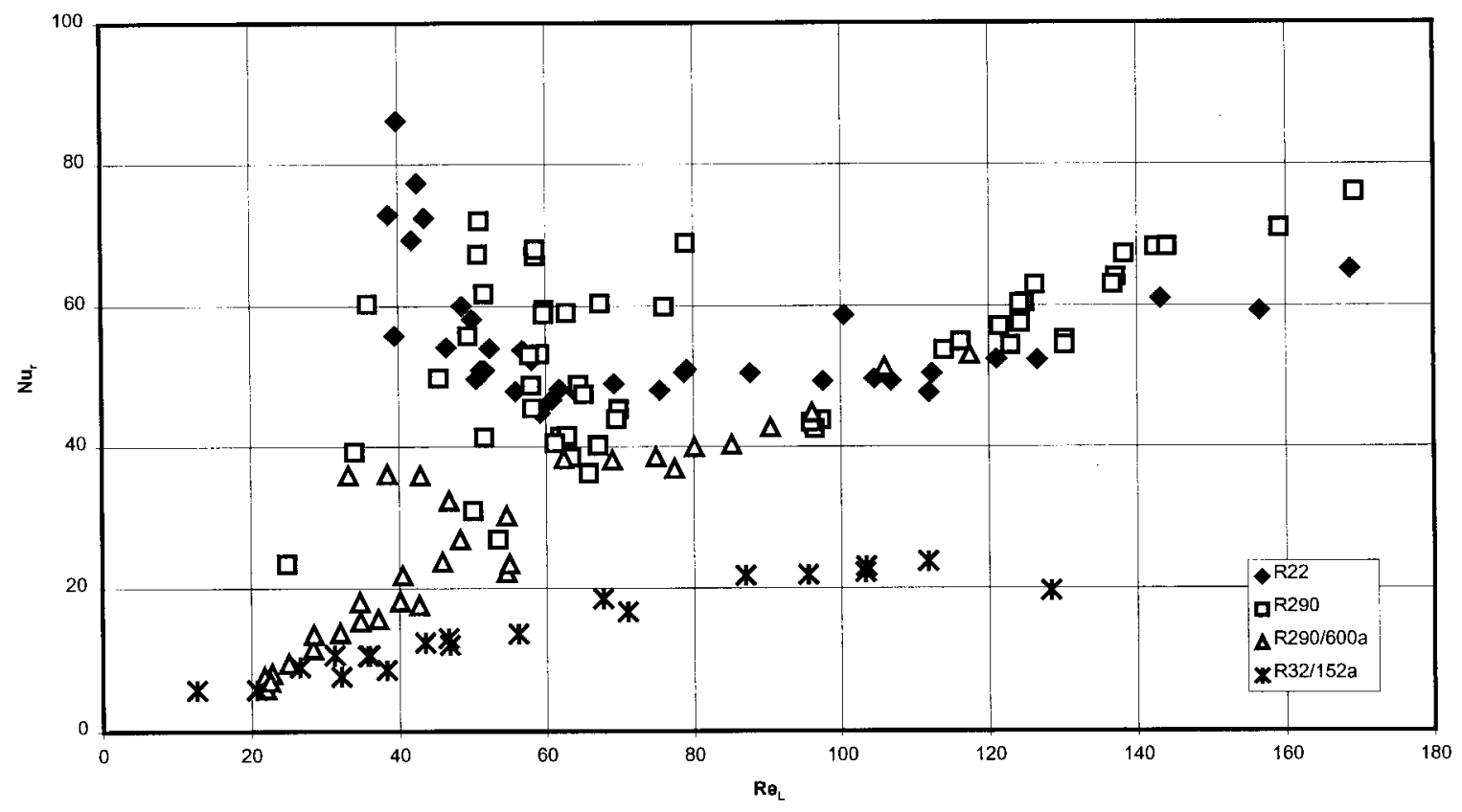

Figure 7. Comparison of evaporative Nusselt numbers for refrigerants in current study.

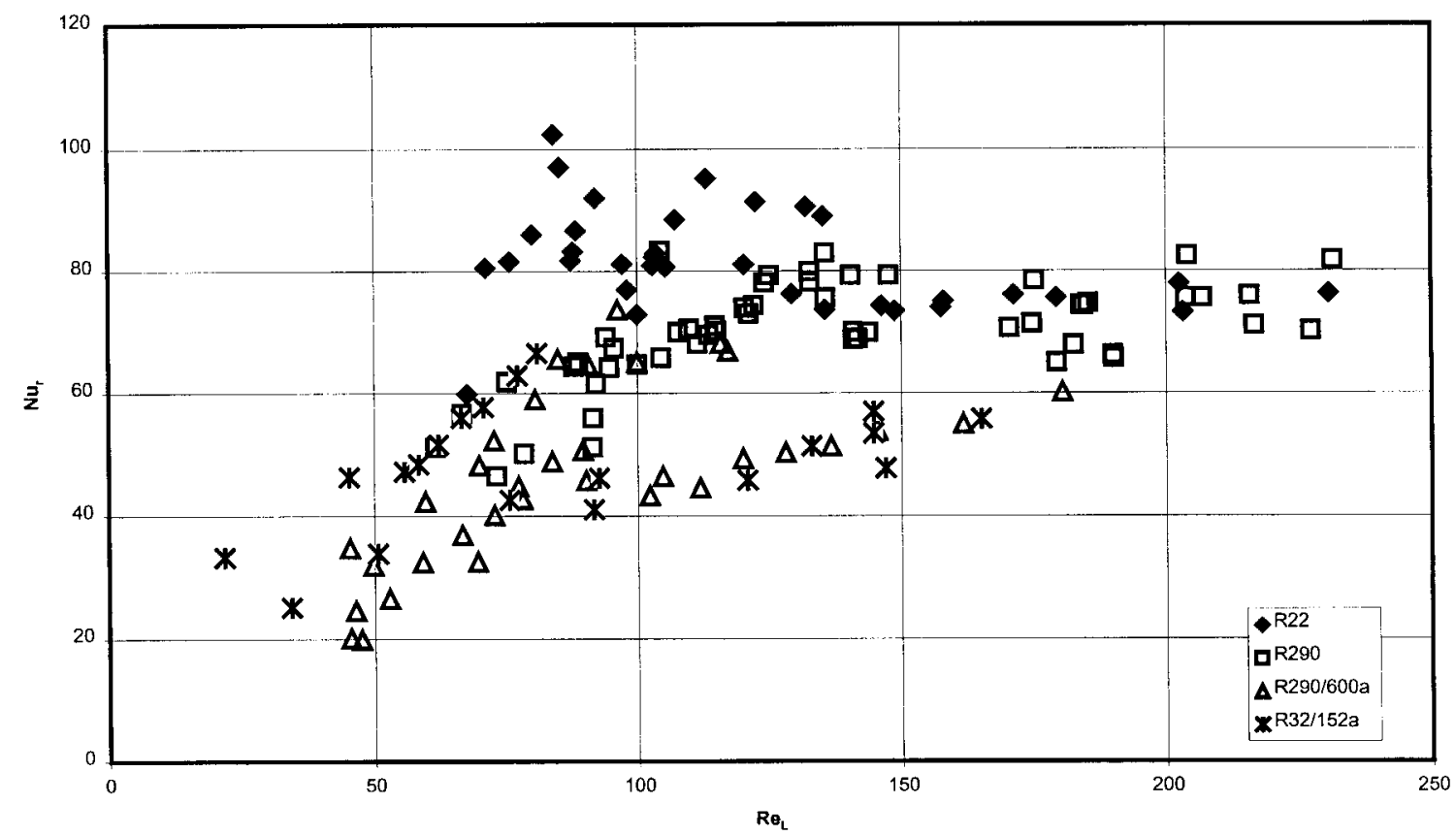

Figure 8. Comparison of condensation Nusselt numbers for refrigerant in current study. 


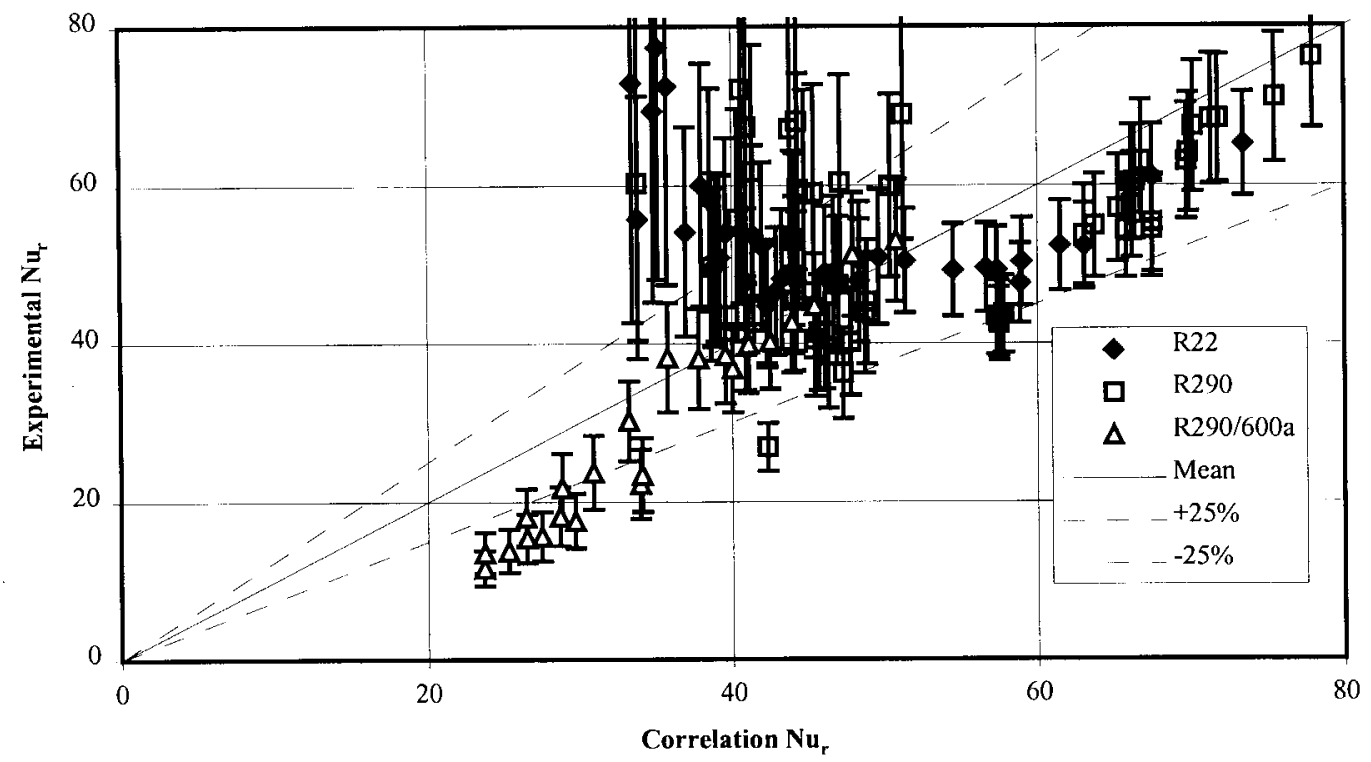

Figure 9. Evaporative Nusselt number correlation for R22, R290, and R290/600a.

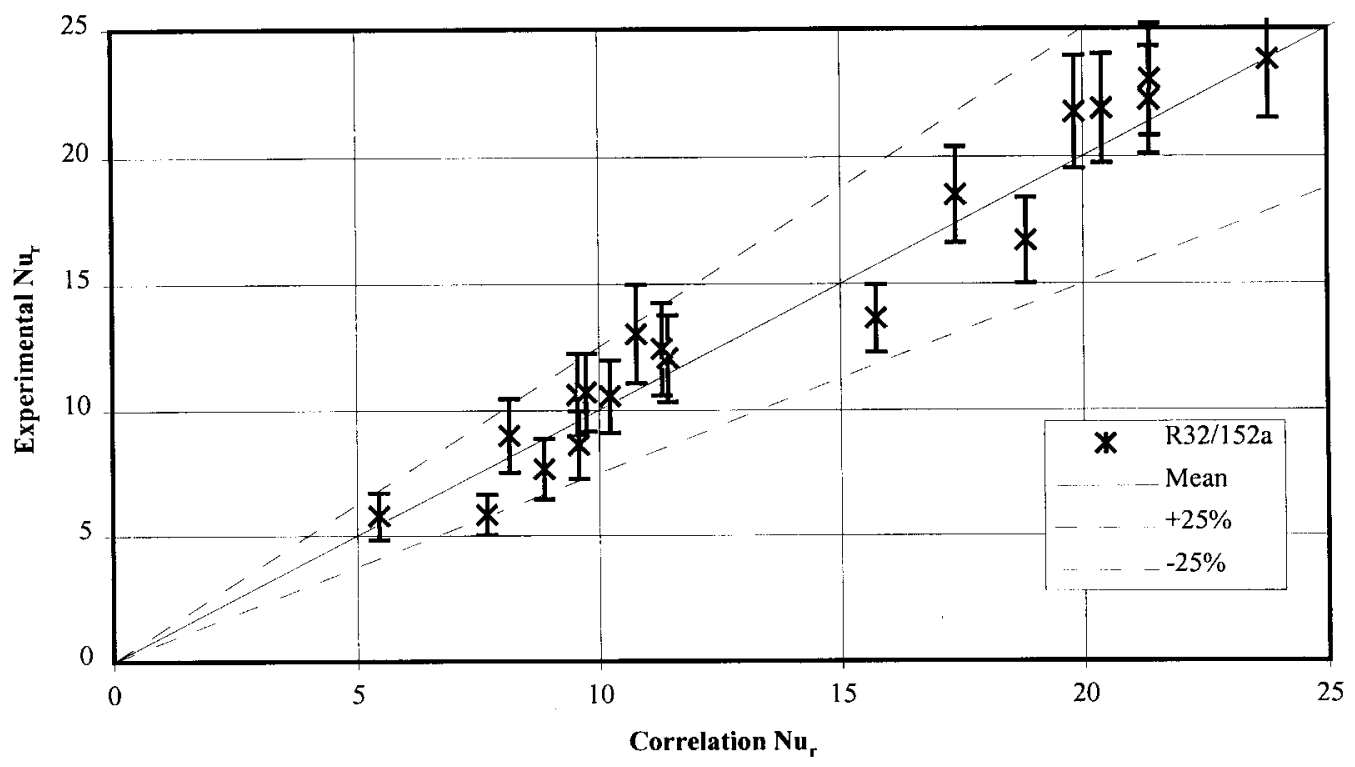

Figure 10. Evaporative Nusselt number correlation for R32/152a. 


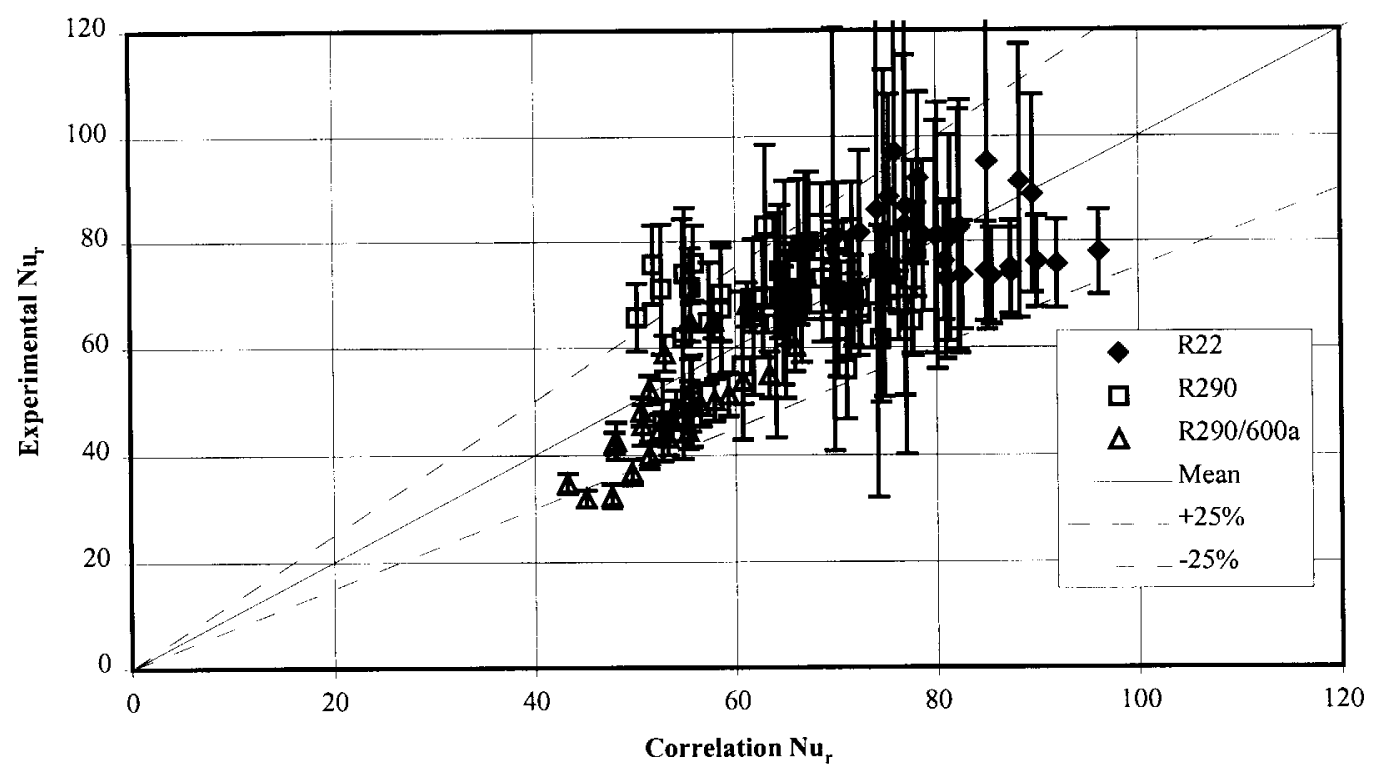

Figure 11. Condensation Nusselt number correlation for R22, R290, and R290/600a.

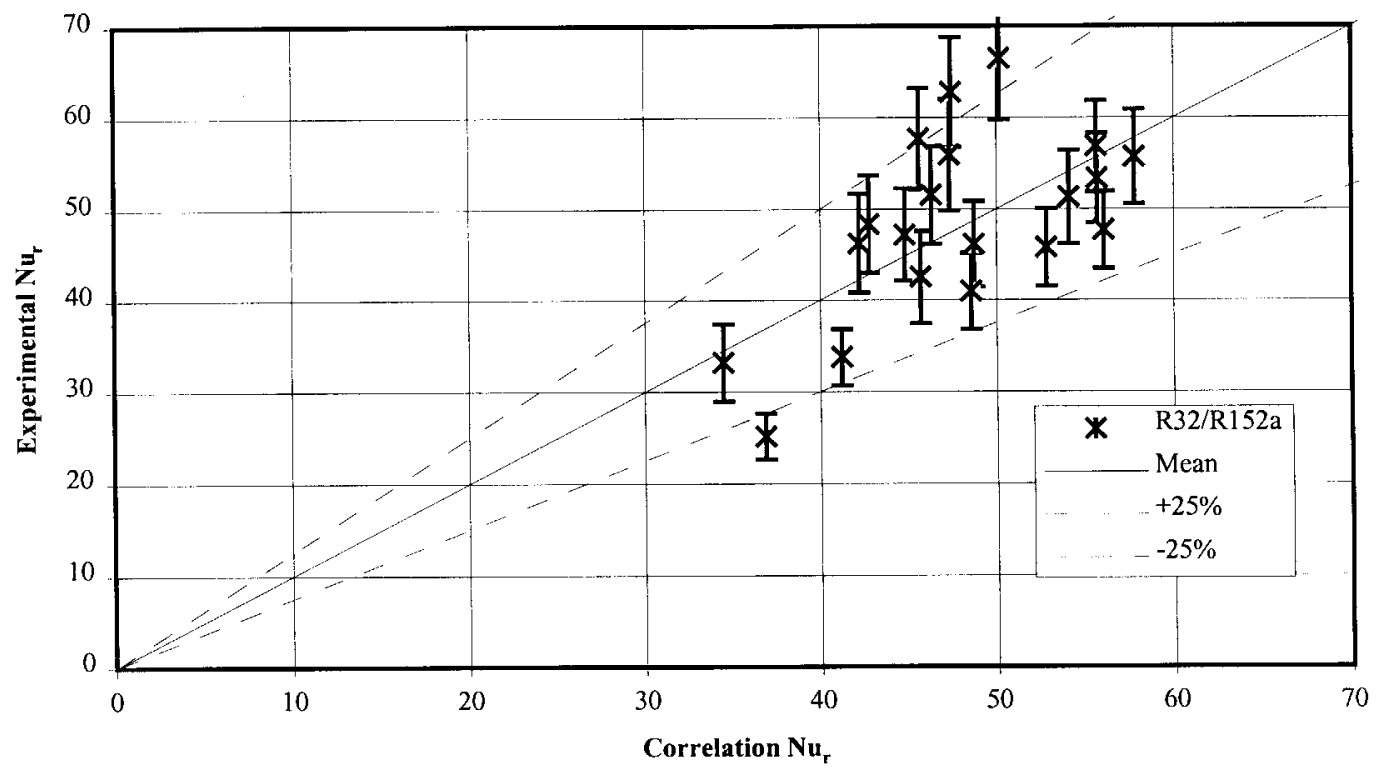

Figure 12. Condensation Nusselt number correlation for R32/152a. 
